OPEN ACCESS

Edited by:

Xiang Zhou,

Fudan University, China

Reviewed by:

Izumi Horikawa,

National Institutes of Health $(\mathrm{NIH})$,

United States

Smrithi Rajendiran,

University of California, Santa Cruz,

United States

*Correspondence:

Md Ataur Rahman

ataur1981rahman@hotmail.com

Bonglee Kim

bongleekim@khu.ac.kr

${ }^{+}$These authors have contributed equally to this work

Specialty section:

This article was submitted to Molecular and Cellular Oncology,

a section of the journal

Frontiers in Cell and Developmental

Biology

Received: 19 August 2021 Accepted: 04 January 2022

Published: 26 January 2022

Citation:

Rahman MA, Park MN, Rahman MDH, Rashid MM, Islam R, Uddin MJ,

Hannan MA and Kim B (2022) p53 Modulation of Autophagy Signaling in Cancer Therapies: Perspectives Mechanism and Therapeutic Targets.

Front. Cell Dev. Biol. 10:761080. doi: 10.3389/fcell.2022.761080

\section{p53 Modulation of Autophagy Signaling in Cancer Therapies: Perspectives Mechanism and Therapeutic Targets}

\begin{abstract}
Md Ataur Rahman ${ }^{1,2,3 * \dagger}$, Moon Nyeo Park ${ }^{1,2 \dagger}$, MD Hasanur Rahman ${ }^{4,5}$, Md Mamunur Rashid $^{6}$, Rokibul Islam ${ }^{7,8}$, Md Jamal Uddin ${ }^{5,9}$, Md Abdul Hannan ${ }^{10}$ and Bonglee Kim ${ }^{1,2 *}$

${ }^{1}$ Department of Pathology, College of Korean Medicine, Kyung Hee University, Seoul, South Korea, ${ }^{2}$ Korean Medicine-Based Drug Repositioning Cancer Research Center, College of Korean Medicine, Kyung Hee University, Seoul, South Korea, ${ }^{3}$ Global Biotechnology \& Biomedical Research Network (GBBRN), Department of Biotechnology and Genetic Engineering, Faculty of Biological Sciences, Islamic University, Kushtia, Bangladesh, ${ }^{4}$ Department of Biotechnology and Genetic Engineering, Bangabandhu Sheikh Mujibur Rahman Science and Technology University, Gopalganj, Bangladesh, ${ }^{5}$ ABEx Bio-Research Center, Dhaka, Bangladesh, ${ }^{6}$ Department of Oncology, Lombardi Comprehensive Cancer Center, Georgetown University Medical Center, Washington, DC, United States, ${ }^{7}$ Department of Biotechnology and Genetic Engineering, Faculty of Biological Sciences, Islamic University, Kushtia, Bangladesh, ${ }^{8}$ Department of Biochemistry, College of Medicine, Hallym University, Chuncheon, South Korea, ${ }^{9}$ Graduate School of Pharmaceutical Sciences, College of Pharmacy, Ewha Womans University, Seoul, Korea,

${ }^{10}$ Department of Biochemistry and Molecular Biology, Bangladesh Agricultural University, Mymensingh, Bangladesh
\end{abstract}

The key tumor suppressor protein p53, additionally known as p53, represents an attractive target for the development and management of anti-cancer therapies. p53 has been implicated as a tumor suppressor protein that has multiple aspects of biological function comprising energy metabolism, cell cycle arrest, apoptosis, growth and differentiation, senescence, oxidative stress, angiogenesis, and cancer biology. Autophagy, a cellular selfdefense system, is an evolutionarily conserved catabolic process involved in various physiological processes that maintain cellular homeostasis. Numerous studies have found that p53 modulates autophagy, although the relationship between p53 and autophagy is relatively complex and not well understood. Recently, several experimental studies have been reported that p53 can act both an inhibitor and an activator of autophagy which depend on its cellular localization as well as its mode of action. Emerging evidences have been suggested that the dual role of p53 which suppresses and stimulates autophagy in various cencer cells. It has been found that p53 suppression and activation are important to modulate autophagy for tumor promotion and cancer treatment. On the other hand, activation of autophagy by p53 has been recommended as a protective function of p53. Therefore, elucidation of the new functions of p53 and autophagy could contribute to the development of novel therapeutic approaches in cancer biology. However, the underlying molecular mechanisms of p53 and autophagy shows reciprocal functional interaction that is a major importance for cancer treatment and manegement. Additionally, several synthetic drugs and phytochemicals have been targeted to modulate p53 signaling via regulation of autophagy pathway in cancer cells. This review emphasizes the current perspectives and the role of p53 as the main regulator of autophagy-mediated novel therapeutic approaches against cancer treatment and managements. 


\section{INTRODUCTION}

Autophagy, a self-degradative intracellular process, is an essential mechanism of the cell that facilitates renewal or removal of cellular molecules, thereby balancing the cell's energy consumption and maintaining homeostasis (Rahman and Rhim, 2017; Rahman et al., 2020a). However, autophagy deregulation is now considered to be one of the most characteristic features for tumor progression (White, 2015). It has recently been revealed that autophagy suppression and a combination of chemotherapeutic treatment have been approached as a potential treatment for cancer (PerezHernandez et al., 2019), although this depends on the context and type of cancer. To date, numerous tumor suppressor oncogenes and proteins have emerged as eminent autophagy regulators whose mutation or depletion regulates autophagy as well as tumorigenesis. Evidences have been suggested that p53 which belonging to the tumor suppressor genes may act as an inhibitor or activator of autophagy depending on their mode of action and subcellular localization (Lacroix et al., 2020). Morevoer, physiological role of autophagy in cancer offers a highest possible target for future cancer therapy and is, hence, presently intensively investigated. Therefore, understanding p53 regulation and its role in individual cellular contexts with a suitable approach of autophagy-mediated regulation in cancer is crucial for drugs development that might be targeted autophagy in a specific diseases model.

Tumor suppressor p53 has been implicated in a wide variety of cellular processes, including genomic stability, cell-cycle arrest, DNA repair, apoptosis, cellular senescence, and autophagy (Aubrey et al., 2018; Mrakovcic and Frohlich, 2018). Generally, p53 binds to DNA in the nucleus which regulates transcription of target genes to activate apoptosis (Tang et al., 2021b). Nevertheless, human p53 mutation has been encouraged tumor progression, chemoresistance, and apoptosis (AlvaradoOrtiz et al., 2021). Additionally, p53 inactivation is effectively used as a therapeutic target of a promising approach to trigger anti-cancer therapy (Zawacka-Pankau and Selivanova, 2015). Thus, p53 has a dual role as a positive or negative regulator of autophagy in cancer (Liu and $\mathrm{Gu}, 2021$ ). Under normal cellular conditions, p53 has been recognized as an autophagy inhibitor, while in response to stress or starvation, p53 might be translocated into the nucleus which endorsed autophagy via transactivation with its target genes (Mrakovcic and Frohlich, 2018; Fang et al., 2021). p53 functions have been modulated via several post-translational modifications as well as different interacting proteins (Soussi, 2000). Among them, 14-3-3 family proteins play an important function in p53 regulation in response to DNA damage (Falcicchio et al., 2020). However, reasons for this difference in wild-type and mutant p53 activities have been triggered apoptosis and cell cycle arrest remain unclear (Parrales and Iwakuma, 2015). Particularly, experimental studies have been confirmed that mutant with gain-of-function variant of p53 in tumors cells are characterized via a higher genomic instability in response to reduce chemotherapeutic which has usually poor prognosis for patients (Liu et al., 2012). In this review, the molecular mechanisms and regulation of autophagy in cancer would be discussed regarding modulation of p53. Additionally, recent progress of autophagy signaling in tumor microenvironment in addition to its targeting for possible cancer therapeutics developments from the pre-clinical trials anong with the challenges in developing autophagy-based cancer therapy (Mukhopadhyay et al., 2021). Therefore, current approaches triggering p53-mediated autophagy regulation in cancer treatment are highlighted and summarized in cancer cells to conventional treatments which are able to overcome chemoresistance in cancer.

\section{METHODS}

Literature-based online databases, Google Scholar, Web of Science, PubMed, Google, and Scopus were accessed to collect information on the published articles that reported molecular mechanism of $\mathrm{p} 53$ and autophagy modulation in cancer prevention. Several keywords were used in the search, such as p53, autophagy, cancer, phytochemicals, natural compounds, solid tumors, and lymphomas perspectives role of p53 and autophagy in cancer therapy. Figures were created with the Adobe Illustrator software.

\section{BIOLOGICAL FUNCTION OF P53 SIGNALING IN CANCER}

The $\mathrm{p} 53$ is a central transcription factor that has the capacity to induce diverse cellular responses likely DNA damage repair, cell cycle arrest, apoptosis, and senescence followed by various stress signals (Figure 1) (Subburayan et al., 2018; Mijit et al., 2020). The master biological function of p53 is to ensure the safety of the DNA uprightness of the cell (Munroe et al., 2020). Along with this, p53 protein operates some additional acts in cellular aging, cell differentiation, and development (Jain and Barton, 2018). The p53 antitumor function is broadly governed by dual approaches; it can promote repair of the DNA damage or promote apoptosis or autophagy to completely remove the irreplaceable damaged materials or cells (Crighton et al., 2006; Janicke et al., 2008). In fact, p53 is a transcription factor of the nucleus which governs the diverse array of cellular processes and escorts transcription of a broad group of target genes of it. At the initial phase of DNA damage, p53 activates and induce cell-cycle arrest of G1-phage which is attributed to repair the DNA damage by promoting the transcription of p21WAF1, GADD45, and p53R2 (He et al., 2020). Following the DNA repair, cells can start come back into the regular cell cycle procedure resulting in p53 itself regulate nuclear integrity to prohibit tumor induction or occurrence (Williams and Schumacher, 2016; Cafaro et al., 2020). On the other hand, p53 is able to apply its pro-apoptotic activities 


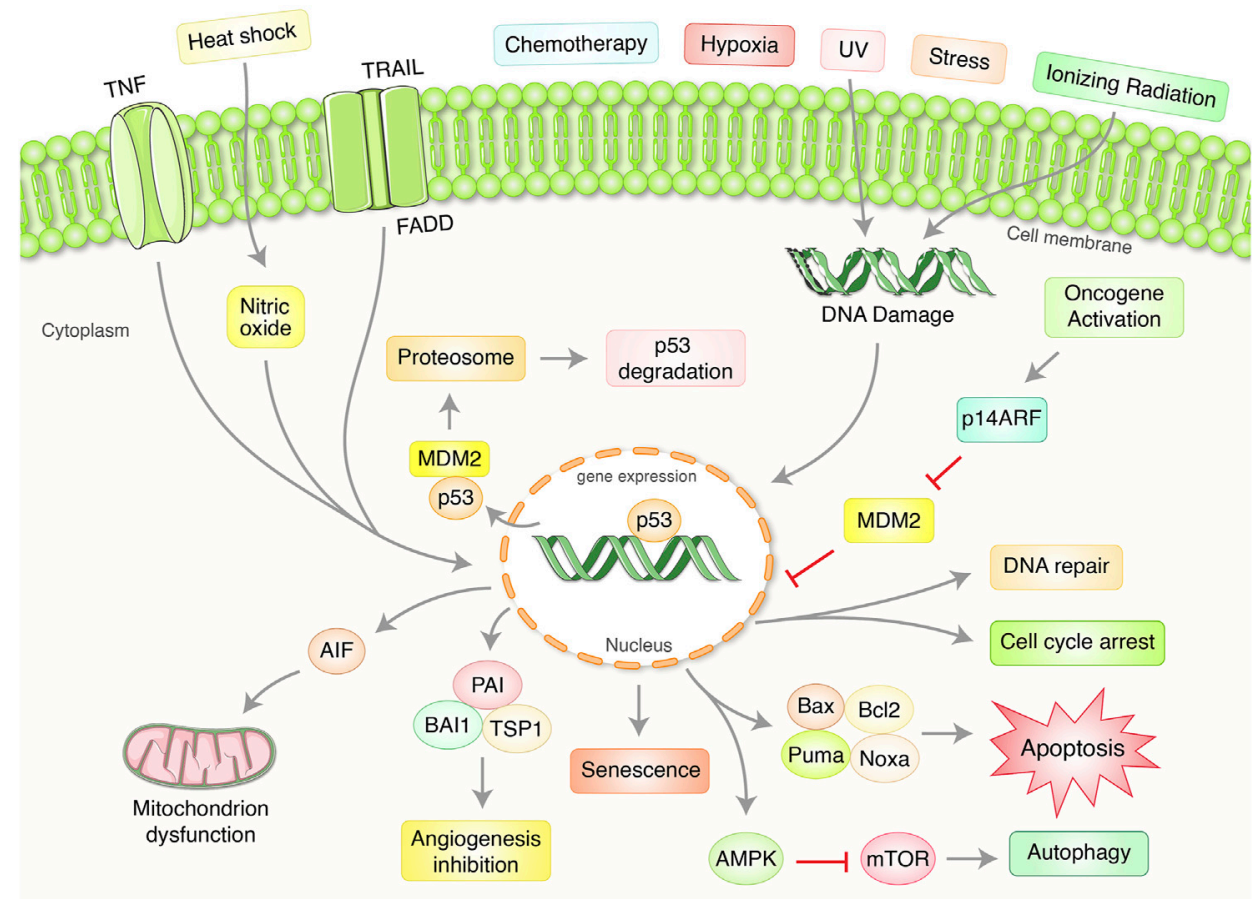

FIGURE 1 | Importance and regulation of tumor suppressor p53 pathway in the regulation of cancer. p53 protein plays an essential role in coordinating with a complex signaling network which regulate aberrant cell proliferation and growth. Normally, p53 has preserved at low steady-state levels with crucial regulation of two proteins, murine double minute 2 (MDM2) as well as MDMX. MDM2 mediates an attachment of ubiquitin (Ub)-mediated proteasomal degradation. Exposure to ultraviolet (UV) light and ionizing radiation activate several kinases and damaging stressors. Oncogenes overexpression has been found to stimulate the production of alternative reading frame (ARF), p14ARF in human and p19ARF in mouse, which binds to MDM2 as well as stabilizes p53. Activation of p53 protein has been targeted to transactivate numerous gene expressions depending on the stressors and the cell type which significantly control either DNA repair, cell cycle arrest, senescence, apoptosis, mitochondrion regulation, autophagy, and angiogenesis.

through the removal of the damaged cells (Ingaramo et al., 2018). In this cellular process, p53 is responsible for the transactivation of a wide range of pro-apoptotic target genes that encodes Bax, Bak, Puma, and Noxa proteins belong to $\mathrm{BH}-3$ only protein and playing a role to promote apoptosis in a cell (Moll et al., 2006; Labi et al., 2008) (Figure 1). In this manner, p53 can protect from tumorigenesis or cancer initiation by regulating this complex process.

\section{Role of Mutant p53 Contributes to Autophagy Regulation in Cancer}

It has been found that mutant p53 proteins are involved in different autophagic pathways vai degrading and targeting to explore the potential approaches in cancer through autophagy (Shim et al., 2021). p53 mutant has designated as a gain-ofoncogenic function(s) (GOFs) which improved cell migration, proliferation, as well as invasion with anti-apoptotic functions which dynamically contribute to numerous phases of tumor progression in cancer (Dittmer et al., 1993; Oren and Rotter, 2010). The changes beyond cancerous are subjected to deliberate discriminating benefits such as facilitating angiogenesis, continuous growth avoiding growth signal, insensitivity to cancer drugs, promotes adequate metabolism, escape from apoptosis with the self-sufficiency of stress signal and ultimately promoting metastasize and invasion (Chatterjee and Viswanathan, 2021; Hernandez Borrero and El-Deiry, 2021). Furthermore, growing evidences from in vitro and in vivo have signified that the oncogenic activities of p53 mutant variants have heterogeneous which can vary with tissue type in addition to genetic background of the cells (Eriksson et al., 2017). Almost 50\% of the p53 gene is mutated in cancer cells, which underlying its normal role in cancer suppression, favors interchange or inactivate the gene which gains a new function that cooperates to sustain the abnormal growth of cancer (Boutelle and Attardi, 2021). Additionally, mutant p53 proteins have been found to exert on autophagy while other mutant p53 activities might affect diverse aspects of cancer biology. It was found that ectopically overexpressing 22 different p53 mutant variants control autophagy in p53 null colon cancer cells (Morselli et al., 2008). p53 ${ }^{\mathrm{R} 175 \mathrm{H}}$ or $\mathrm{p} 53^{\mathrm{R} 273 \mathrm{H}}$ mutants suppresses autophagic vesicles formation and lysosomes fusion via the transcriptional suppression of p53 key downstream responsive autophagy related protein such as DRAM1, BECN1, ATG12, SESN1/2, P-AMPK, and TSC2 (Cordani et al., 2016). Furthermore, protein-protein interactions with other transcription factors as a GOF and some cancer-associated p53 mutants have been shown the capability to block 


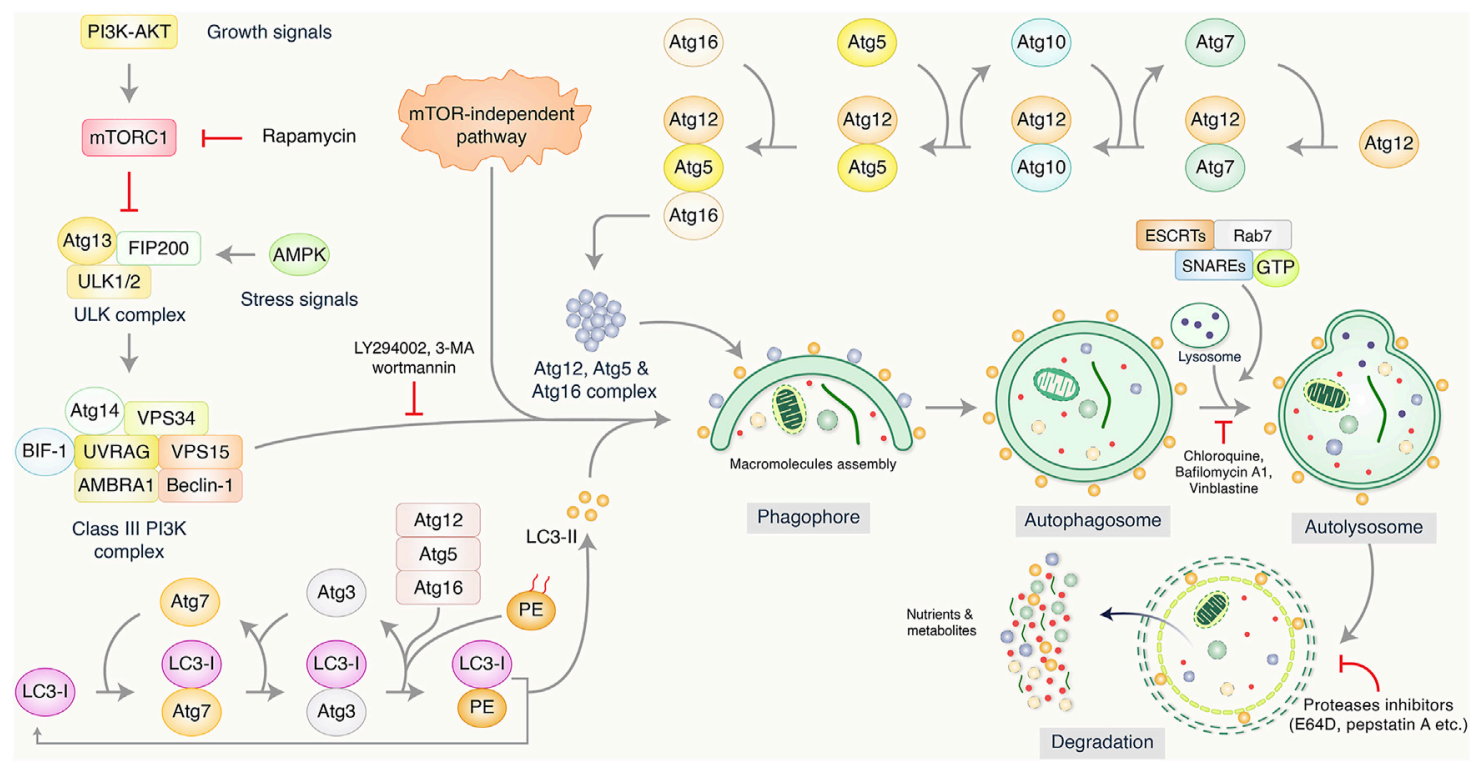

FIGURE 2 |Biological function and molecular mechanism of autophagy pathway. Autophagy has been initiated by the formation of pre-autophagosome structure via the action of several proteins. PI3K-AKT and mammalian target of rapamycin (mTOR) have been influenced to initiate pre-autophagosome assembly via association of ULK1NPS34/Beclin-1 complex. Additionally, Atg5/Atg12/Atg16 and Atg12/Atg5/LC3 complexes are involved to create phagophore nucleation and macromolecules accumulation which has been elongated as well as bind to autophagosome formation. Lysosome binds mature autophagosome by the help of ESCRT/SNARE/ Rab7 protein complex, resulting in autolysosome formation. Finally, autolysosomes have been abolished by acid hydrolases resulting in the release of recycling metabolites as well as nutrients.

autophagy indirectly via triggering numerous growth factor receptors as EGFR, TGFBR, and IGFR which contributing to sustain PI3K/Akt/mTOR signaling and subsequently suppress autophagy in cancer (Aschauer and Muller, 2016). Therefore, targeting of p53 mutant proteins by autophagy inhibition and activation might offer a promising future therapeutic opportunity and is thus presently investigated intensively to modulate autophagy in cancer therapies.

\section{BIOLOGICAL FUNCTION OF AUTOPHAGY IN CANCER}

Autophagy has been categorized as an intracellular selfdegradation mechanism through dysfunctional cytoplasmic organelles and aggregated misfolded proteins are terminated via fusion with lysosomes and double-membrane autophagosomes to maintain cellular homeostasis (Krishnan et al., 2020; Miller and Thorburn, 2021). Usually, autophagy process, mainly macroautophagy, has been initiated via the isolation of pre-autophagosome structures called phagophore assembly sites (PAS) (Hurley and Young, 2017). PI3K related to the endoplasmic reticulum (ER) have a vital role to initiate PAS formation (Kotani et al., 2018). Unc-51 like autophagy activating kinase-1 (ULK1), mammalian target of rapamycin (mTOR), and AMP-activated protein kinase (AMPK) facilitate phagophore formation during induction of autophagy (Alers et al., 2012; Rahman et al., 2021a). Nevertheless, VPS34/UVRAG/Beclin-1/ AMBRA1 helps in the phagophore formation (Velazquez and
Jackson, 2018), followed by membrane elongation and autophagosome formation (Rubinsztein et al., 2012). Lysosome binds to mature autophagosome by the association of ESCRT/ SNARE/Rab7 protein complex, resulting in the formation of autolysosomes (Kardideh et al., 2019; Rahman et al., 2021c). Finally, autolysosomes that contain misfolded/aggregated proteins have been degraded via acid hydrolases and provide recycling metabolites and nutrients for maintaining intracellular homeostasis (Figure 2). It has been found that cancer cell fate regulations and development depended on the autophagy process (Wei and Huang, 2019).

Additionally, well-known cellular autophagy mechanism contributing to carcinogenesis is chaperone-mediated autophagy (CMA) which signify lysosomal-mediated degradation process to facilitate cell survival (Chava et al., 2017). It has been found that during serum starvation, CMA and macroautophagy are triggered consecutively signifying that these two paths are not entirely independent while deficiency or blockage one of this pathway may lead to activate other (Kaushik et al., 2008; Cuervo and Wong, 2014). However, CMA has been found to degrade mutant p53 in a lysosome-dependent fashion in cancer cells under nonproliferating conditions (VakifahmetogluNorberg et al., 2016). Later, chaperone-assisted selective autophagy (CASA) was found in skeletal muscle cells which coordinates protein synthesis and degradation and act as an important physiological stimulus crucial for cellular development, respiratory, maintain urogenital systems, and homeostasis of locomotory (Ulbricht et al., 2013). Moreover, CASA machinery ensures proteostasis in addition to regulate 


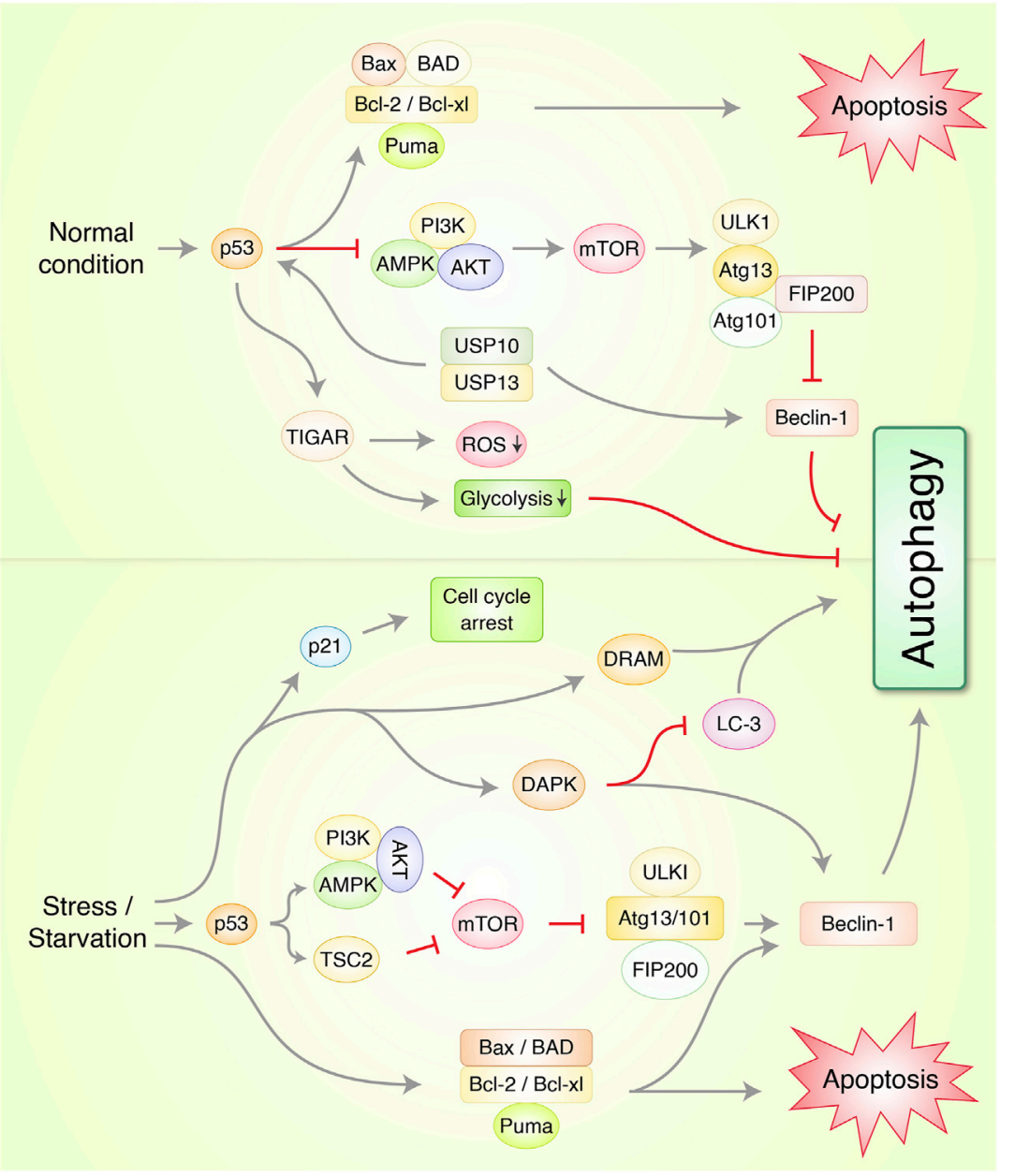

FIGURE 3 | Molecular mechanism of autophagy and apoptosis via p53 regulation in cancer under normal and stress conditions. In normal condition, p53 protein prevents autophagy-mediated cell death via induction of Beclin-1 degradation through ubiquitin-specific peptidases USP10/USP13 and AMPK/mTOR/ULK1 complex activation. TP53-induced glycolysis and apoptosis regulator (TIGAR) prevents autophagy through suppression of reactive oxygen species (ROS) and glycolysis formation. Under stress/starvation condition, p53 activates AMPK and tuberous sclerosis complex 2 (TSC2) which suppresses mTOR and ULK1/FIP200 complex which finally stimulates autophagy. Cyclin-dependent kinase inhibitor 1, p21, activates and arrests cell cycle via p53-mediated upregulation. Additionally, deathassociated protein kinase (DAPK), and damage-regulated autophagy modulator (DRAM), autophagy-related protein Beclin-1 upregulation initiates autophagy. Bcl-2 family, Bcl-2, Bcl-xl, Bax, Bad, and PUMA activates apoptosis.

essential cellular developments such as proliferation, migration, and adhesion which comprises the molecular chaperones HscA8/ Hsp70 as well as HspB8/Hsp22 alone with the co-chaperones Bag3 and STUB1/CHIP (Liu et al., 2013). Importantly, it is found that CASA is essential for muscle maintenance (Arndt et al., 2010). Therefore, HscA8/Hsp70 and HspB8/Hsp22 compex and CASA play an significant function in protein quality control of cancer cells.

Accumulating evidence indicated that autophagy could decide whether cancer cells are promoted or suppressed in certain conditions (Rahman et al., 2020a). In that case, mTOR has an essential function either cellular function becomes an oncogenic activating or protective via inactivation or induction of autophagy pathway (Uddin M. S. et al., 2020; Rahman et al., 2021b). In addition, chemotherapeutic drugs were shown to suppress tumor cells by autophagic modulation (Rahman et al., 2020b). Also, autophagy inhibition has been regulated in cancer progression which decides whether autophagy influences cell death or cell survival function (Jung et al., 2020). Furthermore, epigenetic and genetic function might be alternated the Atgs gene expression which has a greater impact on cancer cell survival. Thus, autophagy modulation of cancer cells has been found to examine the distribution of tumor microenvironment progression which contributes to the potential management and prevention of cancer (Rahman et al., 2020b). Therefore, p53 may react to different kinds of stress as well as damage employed on the cell which comprise endogenous- or environmentally-stressed genotoxicity, oxidative stress, and oncogene activation in order to protect cell damage as well as maintain cellular integrity in cancer (Liu and Gu, 2021). Nevertheless, how posttranslational modifications of p53 postulate its selectivity for each of these transcriptional targets 


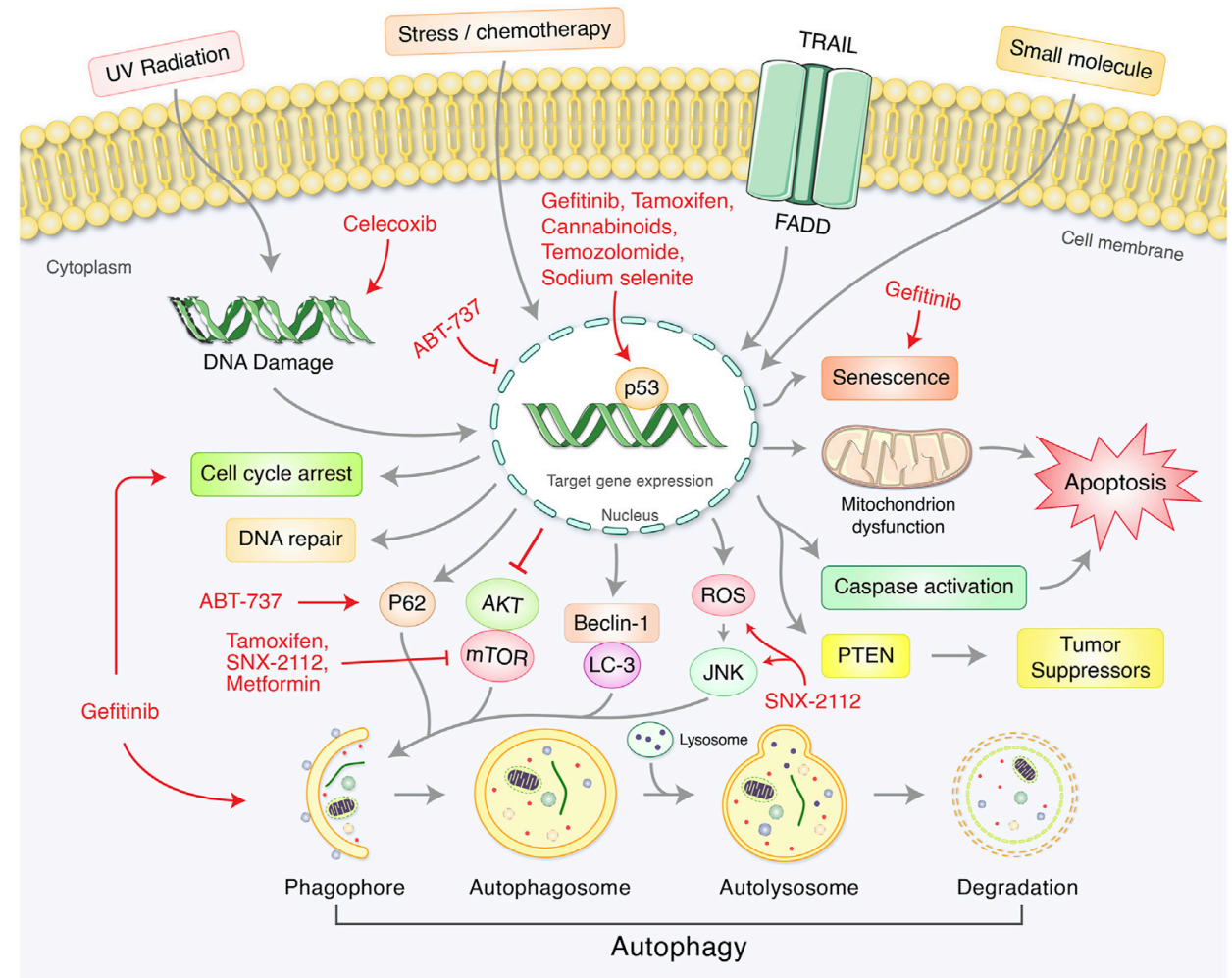

FIGURE 4 | Synthetic drugs targets for p53-mediated autophagy modulation in cancer therapy.

as well as the particular cellular function which induce autophagy in cancer is still unclear.

\section{P53 SIGNALING TARGETS AS A CANCER THERAPY VIA MODULATION OF AUTOPHAGY}

Cell death regulation is a complicated process of maintaining cellular homeostasis by preventing oncogenic growth and recycling damaged cell debris (Rangel et al., 2021). Dysregulation of autophagic cell death occurs frequently in a variety of malignancies and poses a barrier to current therapy development Rahman et al., 2020. Autophagy plays a critical role in both tumor promotion and suppression. Autophagosomes engulf and digest cell organelles and proteins, which are then recycled to restore homeostasis and cellular metabolism (Duffy et al., 2015). In recent years, it has been proposed that the suppression of autophagy in combination with chemotherapy could be used as an innovative way to treat cancer (Figure 3). Interference with the autophagic machinery, on the other hand, can promote or disrupt carcinogenesis, depending on the type of cancer and their environment. It is, therefore, critical to uncover the primary signaling mechanisms that control carcinogenesis and regulate autophagy (Mrakovcic and Frohlich, 2018). Recently, it has been found that autophagy enhanced the stemness of lung CSCs via degrading ubiquitinated p53, therefore relieving cytosolic p53 inhibition of autophagy through generating stable human lung CSC cell lines of wildtype TP53 (A549) where TP53 has been deleted (H1229) (Wang J. et al., 2021).

The research to date has found several tumor suppressor proteins and oncogenes to be essential regulators of autophagy. The loss or mutation of these proteins contributes to tumor formation. In addition to being one of these tumor suppressors, the mammalian cell "janitor" p53 may be one of the most frequently mutated genes in human tumors. Most human cancers exhibit p53 mutation, which is found in approximately half of all tumors (Soussi and Wiman, 2007; Shi Y. et al., 2020). P53 activation is dependent on various stressors, such as DNA damaging agents, oncogenes, and hypoxia, as well as others, and leads to changes in cell cycling, apoptosis, senescence, metabolism, differentiation, as well as angiogenesis inhibition and autophagy control (Giaccia and Kastan, 1998; Levine and Abrams, 2008). From the results of recent experimental research, it has been ascertained that $\mathrm{p} 53$ has both an activator and an inhibitor function with regard to autophagy, depending on its cellular localization and the way of operations (Mrakovcic and Frohlich, 2018). p53 may play a pro-autophagic role in the nucleus, both in a transcription-dependent and independent manner. In the cytoplasm, on the other hand, p53 is known to suppress the induction of autophagy (Maiuri et al., 2010). Recently, it has been highlighted that interplay between proinflammatory/pro-oncogenic and pro-inflammatory cytokines 


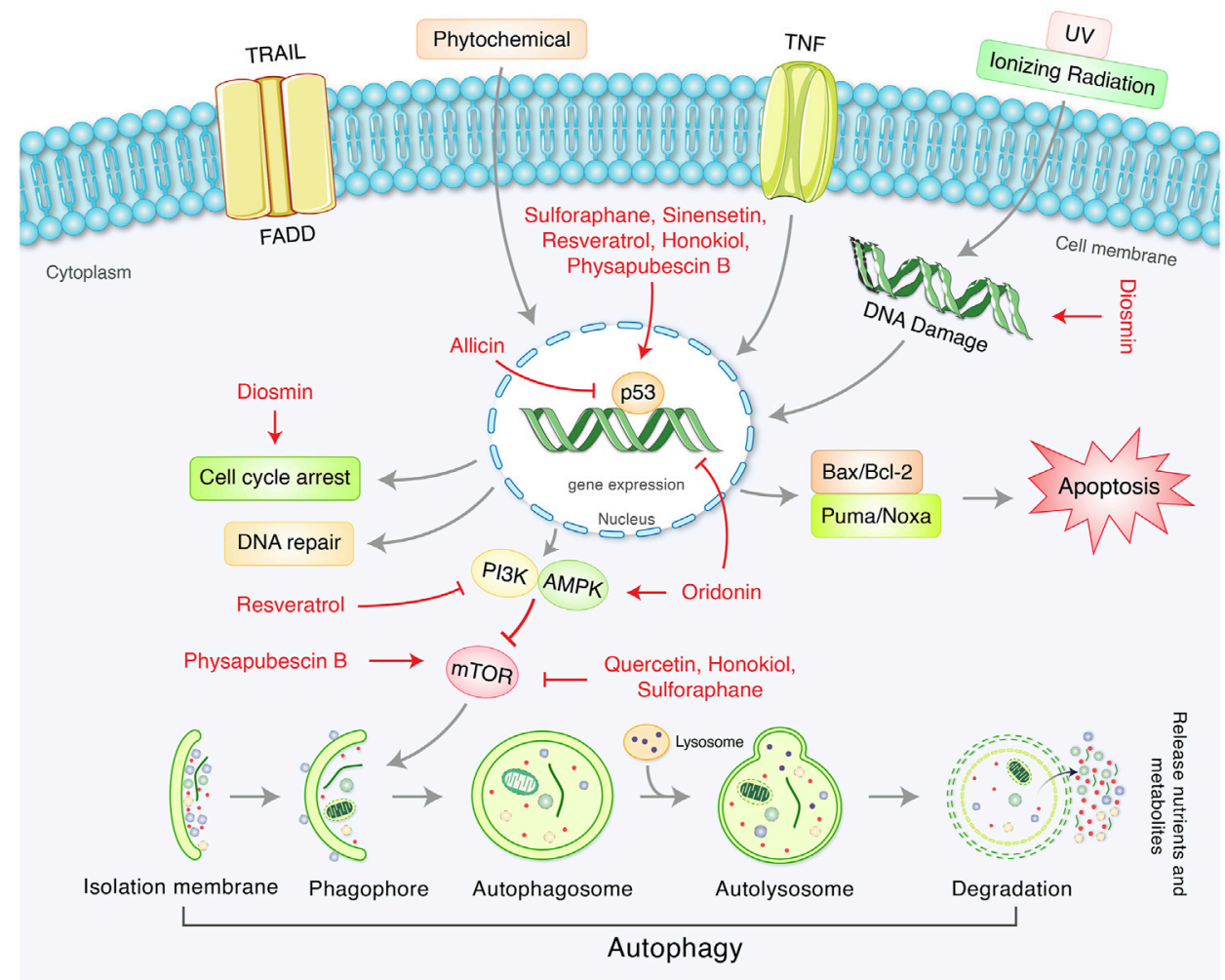

FIGURE 5 | Therapeutic actions of phytochemicals and their targeted signaling system in p53-mediated autophagy regulation in cancer.

pathways regulated via UPR signaling as well as autophagy which affects the stability of p53 that is able to control UPR signaling, cytokine release, and autophagy to preserve its own stability in additional to promote tumorigenesis against cancers carrying mutp53 (D’Orazi et al., 2021).

There are many different cell stressors that might activate p53 (Punja et al., 2021). It is possible that activated p53 may downregulate the autophagy negative regulator, mTOR, through transcriptional regulation of Sestrin1 and Sestrin2, which activate AMPK, which then phosphorylates tuberous sclerosis 2 protein (TSC2) (Budanov and Karin, 2008; Maiuri et al., 2009). In addition to AMPK $\beta 1$ and $A M P K \beta 2$, p53 can transactivate other AMPK $\beta$ subunits including TSC2, PTEN, and IGF-BP3. All of these AMPK $\beta$ subunits can be upregulated in response to a stress signal, and upon this elevation, the p53dependent negative regulation of the mTOR pathways takes place (Feng et al., 2007; Eby et al., 2010). All of these AMPK subunits are capable of being upregulated in response to a stress signal, and this upregulation results in the p53-dependent negative regulation of the mTOR pathways (Jazvinscak Jembrek et al., 2021). A number of targeted genes are activated or inhibited by p53, suggesting that autophagy and cancer prevention are achieved through p53 actions (e.g., activating AMPK and inhibiting mTOR). DRAM (damage-regulated autophagy modulator), a p53 target gene encoding a lysosomal protein that induces macroautophagy, is another mechanism by which p53 promotes the activation of the autophagic pathway. In addition, AEN/ISG20L1 was found to modulate autophagy in response to genotoxic stress by interacting with members of the p53 family (Eby et al., 2010). The three p53 family members (p53, p63, and p73) can regulate transcription of AEN, and downregulation of AEN expression results in decreased levels of autophagic vacuoles and LC3-II, which indicates genotoxic stress. In addition to positive regulators of autophagy, several other pro-apoptotic genes such as PUMA (p53-upregulated modulator of apoptosis) and $\mathrm{Bax}$ (Bcl-2-associated X protein) act as autophagy stimulators. It has been discovered that the protein PUMA, which is only found in the mitochondria, induces mitochondrial autophagy. This function of PUMA is distinct from the function of autophagy induced by starvation or ER stress, which is dependent on the presence of the Bax or Bak proteins. Additionally, mitochondrial-selective autophagy can be induced in the absence of PUMA activation in the presence of only Bax (Yee et al., 2009). These pro-apoptotic genes are likely to induce apoptosis and autophagy in a manner that is closely related. Through its direct physical interaction with the BCL$\mathrm{xL}$ receptor, the $\mathrm{p} 53$-regulated tumor suppressor protein $\mathrm{p} 14 \mathrm{ARF}$ (alternate reading frame protein product of the CDKN2A locus) appears to be able to induce autophagy in human cancer cells (Pimkina et al., 2009; Balaburski et al., 2010). It has been recently confirmed that p14ARF's tumor suppressive properties are achieved through autophagy activation (Verma et al., 2021). Additionally, the same report resolved previous discrepancies between two p14ARF mRNA isoforms and demonstrated that 
autophagy can only be induced by the full-length p14ARF mRNA in the nucleus, while mitophagy is induced by smARF (selective macroautophagy of mitochondria) (Ueda et al., 2008; BudinaKolomets et al., 2013). Studies have found that p53-mediated autophagy begins with DAPK-1 stimulation, with increased gene expression as a secondary response (Zalckvar et al., 2009b). In order to carry out autophagy, DAPK-1 uses two different routes. In the one instance, Beclin-1 phosphorylation inhibits the BCL-2/ BCL-xL-mediated degradation of Beclin-1, while in the other, LC3-interacting MAP1B inhibition keeps autophagy from proceeding (Harrison et al., 2008; Zalckvar et al., 2009a).

It has been reported that in $\mathrm{p} 53^{-/}$cells, only the cytoplasmic p53 can inhibit autophagy through suppressing AMPK and inducing $\mathrm{mTOR}$, resulting in the hyperphosphorylation of AMPK, TSC2, and acetyl CoA carboxylase (ACC) and hypophosphorylation of mTOR substrate, p70S6K (Tasdemir et al., 2008a). Autophagy in HCT116p $53^{-1-}$ colon carcinoma cells is reduced when they are re-transfected with the p53 wild-type allele. Furthermore, when transfected into p53 ${ }^{-/-}$cells, p53 mutants that preferentially localize to the cytoplasm are found to effectively repress autophagy (Morselli et al., 2008). According to all of these observations, it is evident that p53 in the cytoplasm inhibits autophagy. It has been previously shown that TIGAR (TP53-induced glycolysis and apoptosis regulator) has a molecular link to p53's antiautophagic function (Bensaad et al., 2006). Under stressful conditions, inhibition of autophagy by TIGAR, which is a direct target gene of the tumor suppressor gene p53, has been shown to be associated with downregulation of glycolysis and suppression of ROS formation (Bensaad et al., 2009). When TIGAR's function is impaired, ROS levels increase, triggering autophagy induction. Nevertheless, it is unlikely to have an effect on the mTOR pathway (Tang et al., 2021a). It is most likely to have a non-mTOR-mediated metabolic pathway as TIGAR does not appear to have a significant impact on mTOR signaling. The interaction of p53 in embryonic carcinoma cells with Beclin-1 leads to the ubiquitination and degradation of the $\mathrm{p} 53$, which thus suppresses autophagy (Tripathi et al., 2014). By inhibiting cytoplasmic p53, this effect can be reversed, and autophagy can be induced more effectively.

Cancer cells acquire unique metabolic characteristics to ensure their survival and proliferation (DeBerardinis, 2008). Recent studies have been shown that $\mathrm{p} 53$ regulates metabolic traits of cells in addition to its role as a tumor suppressor protein (Wen and Wang, 2021), but the exact mechanism by which p53 regulates metabolism is still not completely understood. As a compensatory response to protect cells against stress, increased signaling triggered by $\mathrm{p} 53$ leads to activation of the PtdIns3KAkt-MAPK-Ras signaling pathway (Corcoran et al., 2006). It was suggested by Gottlieb and Vousden that p53 might be able to counteract the Warburg effect, which is characterized by an abnormally high rate of glycolysis under aerobic conditions and is seen in many cancers (Gottlieb and Vousden, 2010). Recent studies have concluded that p53-regulated metabolism and autophagy are linked which is a primary strategy for cancer treatment to manipulate autophagy regulated by the p53 gene (Shim et al., 2021). A study conducted by Buzzai et al. examined the effect of the anti-diabetic drug metformin on tumor growth in the presence of metformin in the colon cancer cell lines HCT116 $\mathrm{p} 53^{+/+}$and HCT116 $53^{-/-}$, which were isogenic colon cancer cell lines. Autophagy was discovered to be activated in the presence of metformin in HCT116 $\mathrm{p}^{+/+}$cells but not in HCT116 p53 ${ }^{-/-}$ cells in the presence of metformin, which contributed to the continued survival of the cells both in vitro and in vivo (Buzzai et al., 2007; Sui et al., 2011).

\section{THERAPEUTIC ASPECT OF P53 PATHWAY MODULATION OF AUTOPHAGY IN CANCER}

Recently, numerous p53-targeting treatment strategies have been established which includings dendritic cell-derived vaccines, adenoviral p53 vectors, p53-degrading E3 ubiquitin ligase inhibitors of $\mathrm{Mdm} 2$, and small-molecules to reinstate DNA binding activity. For example, a small molecule multi kinase inhibitor, sunitinib, has been permitted to treat metastatic renal cell carcinoma which degrade autophagic induction of wild type p53 proteins in a multiple cancer cell lines (Luo et al., 2018). Additionally, several synthetic and naturally occurring molecules have been targeted to regulate p53-mediated autophagy regulation in cancer. There are several newly discovered drugs and phytochemicals used as MDM2 inhibitors that have shown potential p53-mediated cancer preventive activities in vitro and in vivo. This section will focus on their efficacy and mechanisms of action.

\section{Synthetic Drug Targeting p53-Mediated Autophagy Modulation in Cancer}

Several synthetic chemicals have been used to modulate p53mediated regulation of autophagy signaling in cancer treatment (Table 1, Figure 4). Synthetic cannabinoids was used to induce mitochondrial-mediated apoptotic and autophagy pathways in human LN18, T98G, and U251MG glioblastoma cells deficient in TP53 or PTEN tumor suppressors (Ellert-Miklaszewska et al., 2021). Gefitinib has been found to improve disease outcomes in non-small cell lung cancer (NSCLC) patients via activation of autophagy, apoptosis, senescence, and cell cycle arrest through augmenting the expression of LC3B-II, cleaved caspase-3, p21, and p53 (Zhu et al., 2015). BH3 mimetic, ABT-737, induced autophagy related protein LC-III and decreased P53 in HCT116 colon carcinoma cell lines (Tasdemir et al., 2008b). In HepG2 liver cancer cell, ABT-737 increased p62, Beclin-1, and p53 (Du et al., 2013). COX-2 inhibitor celecoxib-induced DNA damage, activated p53-dependent G-1 cell cycle arrest and regulated p53dependent autophagy induction in human glioblastoma cells (Kang et al., 2009). Tamoxifen, a first line adjuvant endocrine therapy, was increased peptidylarginine deiminase 2 (PAD2), nuclear p53, cell cycle arrest, and apoptosis via downregulating Akt/mTOR expression in tamoxifen-resistant MCF-7 (MCF7/ TamR) cells (Li et al., 2019). In contrast, Hsp90 inhibitor SNX2112 enhanced cellular apoptosis via ROS-mediated autophagy pathway in human cervical cancer cells (Hu et al., 2019). 
TABLE 1 | Several therapeutic drugs targeting p53-mediated autophagy regulation in cancer therapy.

\begin{tabular}{|c|c|c|c|c|c|}
\hline Serial & Drugs & Model/Cancer type & $\begin{array}{l}\text { Mechanism of } \\
\text { p53 modulation }\end{array}$ & $\begin{array}{l}\text { Autophagic } \\
\text { condition }\end{array}$ & References \\
\hline 1 & $\begin{array}{l}\text { Synthetic } \\
\text { cannabinoids }\end{array}$ & $\begin{array}{l}\text { Human LN18, T98G, and U251MG } \\
\text { glioblastoma cells }\end{array}$ & Mudulation of mutant p53 & $\begin{array}{l}\text { Inducetion of } \\
\text { autophagy }\end{array}$ & $\begin{array}{l}\text { Ellert-Miklaszewska et al. } \\
\text { (2021) }\end{array}$ \\
\hline 2 & Gefitinib & Non-small cell lung cancer (NSCLC) & Increases p53 expression & Autophagy activation & Zhu et al. (2015) \\
\hline 3 & ABT737 & HCT116 colon carcinoma cell & p53 induction & Autophagy activation & Tasdemir et al. (2008b) \\
\hline 4 & ABT737 & HepG2 liver cancer cell & Activation of p53 & Autophagy induction & Du et al. (2013) \\
\hline 5 & Celecoxib & $\begin{array}{l}\text { Human glioblastoma cells U87MG and LN229 } \\
\text { cells }\end{array}$ & p53 modulation & $\begin{array}{l}\text { Induction of } \\
\text { autophagy }\end{array}$ & Kang et al. (2009) \\
\hline 6 & Tamoxifen & MCF-7 (MCF7/TamR) cells & Activate nuclear p53 & $\begin{array}{l}\text { Induction of } \\
\text { autophagy }\end{array}$ & Li et al. (2019) \\
\hline 7 & SNX-2112 & Cervical cancer cells (HeLa cells) & p53 induction & Activates autophagy & Hu et al. (2019) \\
\hline 8 & Temozolomide & Glioblastoma U87 cells & Modulate p53 & $\begin{array}{l}\text { Induction of } \\
\text { autophagy }\end{array}$ & Lee et al. (2015) \\
\hline 9 & Sodium selenite & Leukemia NB4 cells & Wild type p53 Modulation & $\begin{array}{l}\text { Induction of } \\
\text { autophagy }\end{array}$ & Shi et al. (2020a) \\
\hline 10 & Metformin & HCT116 p53+/+ and p53-/- Colon cancer cell & $\begin{array}{l}\text { Mudulation of p53-deficient } \\
\text { tumor cell }\end{array}$ & $\begin{array}{l}\text { Activatation of } \\
\text { autophagy }\end{array}$ & Buzzai et al. (2007) \\
\hline 11 & Verteporfin & Human osteosarcoma cells- HOS & $\begin{array}{l}\text { p53 ubiquitinated proteins } \\
\text { modulation }\end{array}$ & Autophagy inhibition & Saini et al. (2021) \\
\hline 12 & Doxorubicin & $\begin{array}{l}\text { Human HCC cells (HepG2, Hep3B) SNU387, } \\
\text { and SNU449 }\end{array}$ & $\begin{array}{l}\text { Modulation of p53 de- } \\
\text { ubiquitination }\end{array}$ & Autophagy regulation & Chen et al. (2021) \\
\hline
\end{tabular}

TABLE 2 | Numerous phytochemicals used as a therapeutic target of p53-mediated autophagy modulation in cancer.

\begin{tabular}{|c|c|c|c|c|c|c|}
\hline SI & Phytochemicals & Model/Cancer type & Mechanism of action & $\begin{array}{c}\text { p53 } \\
\text { Condition }\end{array}$ & $\begin{array}{l}\text { Autophagic } \\
\text { condition }\end{array}$ & References \\
\hline 1 & Allicin & Hep G2 liver cancer & AMPK/mTOR/TSC2 activation & $\begin{array}{l}\text { p53 level } \\
\text { decreased }\end{array}$ & $\begin{array}{l}\text { Autophagy } \\
\text { induction. }\end{array}$ & Chu et al. (2012) \\
\hline 2 & Sinensetin & Hep G2 human liver cancer & AMPK/mTOR. inhibition & p53 modulation & $\begin{array}{l}\text { Increases } \\
\text { autophagy }\end{array}$ & Kim et al. (2020) \\
\hline 3 & Luteolin & HCT116. HT-29 colon cancer & Apoptosis activation & $\begin{array}{l}\text { p53 level } \\
\text { increased }\end{array}$ & $\begin{array}{l}\text { Autophagy } \\
\text { Induction }\end{array}$ & Yoo et al. (2021) \\
\hline 4 & Quercetin & $\begin{array}{l}\text { HepG2, Hep3B, MDA-MB-231, } \\
\text { HCT116 }\end{array}$ & $\begin{array}{l}\text { Activation of apoptosis, TFEB, cathepsin B, } \\
\text { cathepsin D, and LAMP-1 }\end{array}$ & $\begin{array}{l}\text { p53 level } \\
\text { increased }\end{array}$ & $\begin{array}{l}\text { Autophagy } \\
\text { induction. }\end{array}$ & $\begin{array}{l}\text { Wang et al. } \\
\text { (2021b) }\end{array}$ \\
\hline 5 & Resveratrol & $\begin{array}{l}\text { HCC human hepatocellular } \\
\text { carcinoma cells }\end{array}$ & $\begin{array}{l}\text { PI3K/Akt and Beclin1, LC3 II, and p62 } \\
\text { activation }\end{array}$ & $\begin{array}{l}\text { p53 level } \\
\text { increased }\end{array}$ & $\begin{array}{l}\text { Autophagy } \\
\text { induction. }\end{array}$ & $\begin{array}{l}\text { Zhang et al. } \\
(2018)\end{array}$ \\
\hline 6 & Mimulone & $\begin{array}{l}\text { Human A549, MCF-7, HCT116, } \\
\text { U2OS cells }\end{array}$ & AMPK/mTOR activation & $\begin{array}{l}\text { p53 level } \\
\text { decreased }\end{array}$ & $\begin{array}{l}\text { Induction of } \\
\text { autophagy }\end{array}$ & An et al. (2014) \\
\hline 7 & Diosmin & MCF-7, MDA-MB-231, SK-BR-3 cell & $\mathrm{p} 21, \mathrm{p} 27$, and ERK1/2 activation & $\begin{array}{l}\text { p53 level } \\
\text { increased }\end{array}$ & $\begin{array}{l}\text { Autophagy } \\
\text { induction. }\end{array}$ & $\begin{array}{l}\text { Lewinska et al. } \\
\text { (2017) }\end{array}$ \\
\hline 8 & Honokiol & Human U87 MG glioma cells & Akt/mTOR downregulation & p53 induction & $\begin{array}{l}\text { Autophagy } \\
\text { induction }\end{array}$ & Lin et al. (2016) \\
\hline 9 & Oridonin & $\begin{array}{l}\text { HCT-15, COLO205, HCT116, RKO, } \\
\text { SW480, and SW620 }\end{array}$ & AMPK deactivated autophagy induction & p53 decresed & $\begin{array}{l}\text { Induction of } \\
\text { autophagy }\end{array}$ & Yao et al. (2017) \\
\hline 10 & Physapubescin B & HeLa and HCT116 & mTORC1 and ROS suppression & p53-dependent & $\begin{array}{l}\text { Autophagy } \\
\text { inhibition }\end{array}$ & Xu et al. (2017) \\
\hline 11 & Sulforaphane & Malignant mesothelioma $(\mathrm{H}-28)$ & Akt/mTOR reduction & $\begin{array}{l}\text { p53 level } \\
\text { increased }\end{array}$ & $\begin{array}{l}\text { Induction of } \\
\text { autophagy }\end{array}$ & $\begin{array}{l}\text { Lee and Lee, } \\
(2017)\end{array}$ \\
\hline 12 & A-24 & $\begin{array}{l}\text { p53 wild-type and-deficient gastric } \\
\text { cancer cells }\end{array}$ & PI3K/Akt/mTOR pathway & p53 modulation & $\begin{array}{l}\text { Autophagy } \\
\text { induction }\end{array}$ & Xu et al. (2021) \\
\hline
\end{tabular}

Temozolomide has been found to induce autophagy and p53 as well as phospho-p53 levels in glioblastoma U87 cells (Lee et al., 2015). Moreover, sodium selenite induced autophagy and apoptosis in p53 wild type cells without caspase-8/apoptosisinducing factor activation and upregulated PLSCR1 in Leukemia NB4 cells (Shi K. et al., 2020). It has been reported that antidiabetic drug, metformin, activated autophagy via mTOR inhibition and AMPK activation in p53-deficient tumor cell growth of cancer HCT116 $\mathrm{p}^{+/+}$and HCT116 $\mathrm{p} 53^{-/-}$cell lines (Buzzai et al., 2007). Furthermore, metformin inhibited matrix metalloproteinase-9 activation, decreased endogenous insulin resistance, suppressed HER2 (erbB-2) oncoprotein overexpression, improved cancer patient's survival in type 2 diabetes, and blocked migration as well as invasion of cancer cells (Sui et al., 2011). Recently, Saini et al. found that verteporfin, known as autophagy inhibitory and proteotoxic functions, 
disrupts multiple steps of autophagy in addition to regulate p53 to sensitize osteosarcoma of human osteosarcoma cells- HOS (R156P mutant P53) (Saini et al., 2021). microRNA, miR-26b, improves the sensitivity of hepatocellular carcinoma to doxorubicin by USP9X-dependent degradation of p53 as well as autophagy regulation (Chen et al., 2021).

\section{Phytochemicals/Natural Products Targeting p53-Mediated Autophagy Regulation in Cancer Therapy}

Phytochemicals from edible as well as medicinal plants have shown to potent cancer chemotherapeutic and chemopreventive activities. Several phytochemicals have mediated their anticancer properties via targeting p53 (Qin et al., 2018) (Figure 5). Numerous phytochemicals/natural products have been used to modulate p53-mediated autophagy pathways as a therapeutic target are presented in Table 2. Allicin reduced cytoplasmic p53, Bcl-2, and inhibited $\mathrm{PI} 3 \mathrm{~K} / \mathrm{mTOR}$ signaling pathway in addition to increase AMPK/TSC2 and Beclin-1 expression in Hep G2 cells (Chu et al., 2012). Sinensetin-mediated autophagy has been involved in $\mathrm{p} 53$-induced $\mathrm{AMPK} / \mathrm{mTOR}$ signaling pathway in HepG2 Cells (Kim et al., 2020). In p53 wild, HCT116 cells, luteolin exhibited anti-cancer effects via the regulation of $\mathrm{p} 53$ through cell cycle arrests such as $\mathrm{PARP} / \mathrm{p} 21$ and apoptosis mediated by Nova and Bax (Yoo et al., 2021). Quercetin, a flavonoid derived from fruits and vegetables, was found to induce p53-independent/mTORC1 mechanism in various cancer cells such as human hepatocellular carcinoma cells (HepG2, Hep3B, MDA-MB-231) and colorectal cancer cells (HCT116, GFP-LC3 Hela cells) (Wang Z. X. et al., 2021). It has been demonstrated that resveratrol inhibited pAkt/Akt and induced autophagy related protein Beclin-1, LC3-II and p62 in HCC cells (Zhang et al., 2018). The anticancer mechanism of mimulone has been mediated by an increase of specific markers of autophagy such as LC3-I and LC3-II along with inhibition of $\mathrm{p} 53, p$-mTOR and increase of p-AMPK (An et al., 2014). Diosmin, derived from citrus fruits, has been identified as a mediator of oxidative and nitrosative stress caused by DNA damage and DNA methylation lead to G2/M cell cycle arrest, elevation in p53, p21, p27 and ERK, mediated by autophagy (Lewinska et al., 2017). Honokiol, a lignan belonging to the genus Magnolia, induced ROS-mediated autophagic cell death via regulating the $\mathrm{p} 53 / \mathrm{PI} 3 \mathrm{~K} / \mathrm{Akt} / \mathrm{mTOR}$ signaling pathway in human U87 MG glioma cells (Lin et al., 2016). Oridonin, a natural diterpenoid isolated from the traditional Chinese herb, activated autophagy through inhibition of glucose metabolism and AMPK inhibition in p53-mutated colorectal cancer cell (Yao et al., 2017). A steroidal compound, physapubescin B, extracted from Physalis pubescens L. (Solanaceae), has been described to possess anti-cancer potential through excessive ROS generation and induce p53-dependent apoptotic cell death by autophagy inhibition in cervical cancer (HeLa) and colon cancer (HCT116) cells (Xu et al., 2017). Sulforaphane (SFN), an isothiocyanate compound found in cruciferous vegetables, potentiates apoptosis and promotes autophagy in malignant mesothelioma cells via activation of p53 (Lee and Lee, 2017; Uddin MS. et al., 2020). A steroidal saponin, A-24, derived from Allium chinense, induced apoptosis and autophagy along with migration inhibition in p53 wild-type as well as p53-deficient gastric cancer cells via ROS accumulation in independent of p53 (Xu et al., 2021).

\section{Perspectives and Limitations of p53-Modulated Autophagy Cancer Therapy}

The role of p53 in autophagy regulation in cancer progression has established into a strongly knit, exciting, and rapidly changing disciple in biological science. However, the study of the ability of p53 to modulate autophagy in addition how this modulation of regulation of cancer metabolism raises numerous issues. The basic process of autophagy is important for normal cellular function as its dysregulation is generally encountered during human tumor development (Yan and Chen, 2021). However, p53 and autophagy comprise a two-edged sword as well as possess an important function in tumor development and progression (Thorburn, 2014; Gao et al., 2020). Depending on the cancer type and entity, p53 and autophagy molecular predisposition in relation to tumor mutations, both can either encourage or inhibit tumorigenesis (Mrakovcic and Frohlich, 2018). There is currently not much evidence of p53-mediated autophagy regulation in cancer metabolism. Recently, it has been found that p53 activates cell cycle arrest in MEFs cell, whereas it induces apoptosis in oncogene-transformed MEFs cell which indicates that p53 exerts its tumor inhibition function in a cell- and tissuedependent manner (Kon et al., 2021). Meanwhile, autophagy activation leads to clearance of subcellular organelle, or autophagic cell atrophy, or autophagic cell death in which tumor suppression occurs upon activation of p53 in a certain type of tissue (Jin, 2005). Additionally, autophagy activation contributes to determining cell fate upon p53 activation (Chen, 2016). However, autophagy downregulation either via mutations of autophagic genes, or activation of mTOR signaling through the activation of an abnormal oncogene might change p53-mediated apoptosis or necrosis with cell cycle arrest (Denisenko et al., 2018). Forthcoming studies would be required to investigate the epigenetic and genetic modifications of autophagy pathway in cancer in the context of p53 tumor suppression. p53 network and mTOR network will not only provide a new understanding of tumorigenesis, but also provide a clue for the target of cancer chemotherapy. Accordingly, the function of normal p53 might be compromised. Furthermore, the consequences of autophagy regulation via p53 modulation for cancer prognosis are quite difficult to predict. The link between p53 and autophagy provide a novel mechanism which p53 might play an important functional role as a guardian of metabolic balance in cancer suppression. These new functional role of p53-mediated autophagy modulation would be provided an interesting potentials for the development of novel cancer therapies. 


\section{CONCLUSION}

The role and impact of modulation of p53 in regulation of autophagy is complex and far from fully clarified. Emerging evidence and rapidly developed omics as well as genome editing techniques have likely been to revolutionized a new $\mathrm{p} 53$ roles in autophagic activities of different $\mathrm{p} 53$ proteins may vary along with changes in tumor microenvironment. Therefore, novel technologies may shed a new perceptions for a knowledgebased insights to recognize gaps-existing knowledge in addition to analyze scenarios which involve a reconsideration for the function of p53 modulation in autophagy signaling in cancer. Recently, autophagy has been established as a dual role in tumor suppression process likely involved in human cancer research. p53 might be an essential player in the modulation of autophagy pathway, although the exact molecular mechanisms and cellular function in cytoplasmic and nuclear p53-mediated autophagy regulation have not been well studied. However, cellular function and role of p53-mediated autophagy, as well as molecular metabolism in cancer progression, require a strongly related and rapidly altering field. The regulation of cancer metabolism by p53 target genes can diverge according to the stress signal, cell type, and other conditions. Additional, it is evidently established that p53 stabilization is a tumor-specific vulnerability, approaches to indorse the degradation of p53 through autophagy which represents an attractive anti-cancer method. Nevertheless, our augmented understanding of the function of p53 and autophagy will hopefully offer a prospective approach to cancer treatment. Therefore, this review revealed that p53 could be targeted as an important implication of cancer therapy via modulation of autophagy signaling. Hitherto the actual therapeutic use of p53-

\section{REFERENCES}

Alers, S., Löffler, A. S., Wesselborg, S., and Stork, B. (2012). Role of AMPK-mTORUlk1/2 in the Regulation of Autophagy: Cross Talk, Shortcuts, and Feedbacks. Mol. Cel Biol 32, 2-11. doi:10.1128/mcb.06159-11

Alvarado-Ortiz, E., de la Cruz-Lopez, K. G., Becerril-Rico, J., Sarabia-Sanchez, M. A., Ortiz-Sanchez, E., and Garcia-Carranca, A. (2021). Mutant P53 Gain-Of-Function: Role in Cancer Development, Progression, and Therapeutic Approaches. Front Cel Dev Biol 8. doi:10.3389/ fcell.2020.607670

An, H.-K., Kim, K.-S., Lee, J.-W., Park, M.-H., Moon, H.-I., Park, S.-J., et al. (2014). Mimulone-induced Autophagy through P53-Mediated AMPK/ mTOR Pathway Increases Caspase-Mediated Apoptotic Cell Death in A549 Human Lung Cancer Cells. PLoS One 9, e114607. doi:10.1371/ journal.pone. 0114607

Arndt, V., Dick, N., Tawo, R., Dreiseidler, M., Wenzel, D., Hesse, M., et al. (2010). Chaperone-Assisted Selective Autophagy Is Essential for Muscle Maintenance. Curr. Biol. 20, 143-148. doi:10.1016/j.cub.2009.11.022

Aschauer, L., and Muller, P. A. J. (2016). Novel Targets and Interaction Partners of Mutant P53 Gain-Of-Function. Biochem. Soc. Trans. 44, 460-466. doi:10.1042/ bst20150261

Aubrey, B. J., Kelly, G. L., Janic, A., Herold, M. J., and Strasser, A. (2018). How Does P53 Induce Apoptosis and How Does This Relate to P53-Mediated Tumour Suppression? Cell Death Differ 25, 104-113. doi:10.1038/cdd.2017.169

Balaburski, G. M., Hontz, R. D., and Murphy, M. E. (2010). p53 and ARF: Unexpected Players in Autophagy. Trends Cel Biol. 20, 363-369. doi:10.1016/j.tcb.2010.02.007 mediated autophagy induction needs detailed knowledge of how the autophagy-lysosomal pathway may affect in cancer progression.

\section{AUTHOR CONTRIBUTIONS}

Idea and conceptualization by MAR. Figures are drawing by MHR. Writing and original draft preparation by MNP, MMMR, RI, MJU, and MAH. Visualization and supervision by BK. All authors have read and agreed to the published version of the manuscripts.

\section{FUNDING}

This research was supported by Basic Science Research Program through the National Research Foundation of Korea (NRF) funded by the Ministry of Education (NRF2020R1I1A2066868), the National Research Foundation of Korea (NRF) grant funded by the Korea government (MSIT) (No. 2020R1A5A2019413), a grant of the Korea Health Technology R\&D Project through the Korea Health Industry Development Institute (KHIDI), funded by the Ministry of Health \& Welfare, Republic of Korea (grant number: HF20C0116), and a grant of the Korea Health Technology R\&D Project through the Korea Health Industry Development Institute (KHIDI), funded by the Ministry of Health \& Welfare, Republic of Korea (grant number: HF20C0038). Additionally, this work was supported by NRF Brain Pool (BP) Program (RI 2020H1D3A1A04104782) funded by the Ministry of Science and ICT, Republic of Korea.

Bensaad, K., Cheung, E. C., and Vousden, K. H. (2009). Modulation of Intracellular ROS Levels by TIGAR Controls Autophagy. EMBO J. 28, 3015-3026. doi:10.1038/emboj.2009.242

Bensaad, K., Tsuruta, A., Selak, M. A., Vidal, M. N. C., Nakano, K., Bartrons, R., et al. (2006). TIGAR, a P53-Inducible Regulator of Glycolysis and Apoptosis. Cell 126, 107-120. doi:10.1016/j.cell.2006.05.036

Boutelle, A. M., and Attardi, L. D. (2021). p53 and Tumor Suppression: It Takes a Network. Trends Cel Biol. 31, 298-310. doi:10.1016/j.tcb.2020.12.011

Budanov, A. V., and Karin, M. (2008). p53 Target Genes Sestrin1 and Sestrin2 Connect Genotoxic Stress and mTOR Signaling. Cell 134, 451-460. doi:10.1016/j.cell.2008.06.028

Budina-Kolomets, A., Hontz, R. D., Pimkina, J., and Murphy, M. E. (2013). A Conserved Domain in Exon 2 Coding for the Human and Murine ARF Tumor Suppressor Protein Is Required for Autophagy Induction. Autophagy 9, 1553-1565. doi:10.4161/auto.25831

Buzzai, M., Jones, R. G., Amaravadi, R. K., Lum, J. J., DeBerardinis, R. J., Zhao, F, et al. (2007). Systemic Treatment with the Antidiabetic Drug Metformin Selectively Impairs P53-Deficient Tumor Cell Growth. Cancer Res. 67, 6745-6752. doi:10.1158/0008-5472.can-06-4447

Cafaro, T., Carnicelli, V., Caprioli, G., Maggi, F., Celenza, G., Perilli, M., et al. (2020). Anti-apoptotic and Anti-inflammatory Activity of Gentiana Lutea Root Extract. Adv. Tradit Med. (Adtm) 20, 619-630. doi:10.1007/s13596-02000447-5

Chatterjee, M., and Viswanathan, P. (2021). Long Noncoding RNAs in the Regulation of P53-mediated Apoptosis in Human Cancers. Cel Biol. Int. 45, 1364-1382. doi:10.1002/cbin.11597

Chava, S., Lee, C., Aydin, Y., Chandra, P. K., Dash, A., Chedid, M., et al. (2017). Chaperone-mediated Autophagy Compensates for Impaired Macroautophagy 
in the Cirrhotic Liver to Promote Hepatocellular Carcinoma. Oncotarget 8, 40019-40036. doi:10.18632/oncotarget.16685

Chen, E., Li, E., Liu, H., Zhou, Y., Wen, L., Wang, J., et al. (2021). miR-26b Enhances the Sensitivity of Hepatocellular Carcinoma to Doxorubicin via USP9X-dependent Degradation of P53 and Regulation of Autophagy. Int. J. Biol. Sci. 17, 781-795. doi:10.7150/ijbs.52517

Chen, J. (2016). The Cell-Cycle Arrest and Apoptotic Functions of P53 in Tumor Initiation and Progression. Cold Spring Harb Perspect. Med. 6, a026104. doi:10.1101/cshperspect.a026104

Chu, Y.-L., Ho, C.-T., Chung, J.-G., Rajasekaran, R., and Sheen, L.-Y. (2012). Allicin Induces P53-Mediated Autophagy in Hep G2 Human Liver Cancer Cells. J. Agric. Food Chem. 60, 8363-8371. doi:10.1021/jf301298y

Corcoran, C. A., Huang, Y., and Sheikh, M. S. (2006). The Regulation of Energy Generating Metabolic Pathways by P53. Cancer Biol. Ther. 5, 1610-1613. doi: $10.4161 /$ cbt.5.12.3617

Cordani, M., Oppici, E., Dando, I., Butturini, E., Dalla Pozza, E., Nadal-Serrano, M., et al. (2016). Mutant P53 Proteins Counteract Autophagic Mechanism Sensitizing Cancer Cells to mTOR Inhibition. Mol. Oncol. 10, 1008-1029. doi:10.1016/j.molonc.2016.04.001

Corona Velazquez, A. F., and Jackson, W. T. (2018). So Many Roads: the Multifaceted Regulation of Autophagy Induction. Mol. Cel Biol 38. doi:10.1128/MCB.00303-18

Crighton, D., Wilkinson, S., O’Prey, J., Syed, N., Smith, P., Harrison, P. R., et al. (2006). DRAM, a P53-Induced Modulator of Autophagy, Is Critical for Apoptosis. Cell 126, 121-134. doi:10.1016/j.cell.2006.05.034

Cuervo, A. M., and Wong, E. (2014). Chaperone-mediated Autophagy: Roles in Disease and Aging. Cell Res 24, 92-104. doi:10.1038/cr.2013.153

D’Orazi, G., Cordani, M., and Cirone, M. (2021). Oncogenic Pathways Activated by Pro-inflammatory Cytokines Promote Mutant P53 Stability: Clue for Novel Anticancer Therapies. Cell Mol Life Sci 78, 1853-1860.

DeBerardinis, R. J. (2008). Is Cancer a Disease of Abnormal Cellular Metabolism? New Angles on an Old Idea. Genet. Med. 10, 767-777. doi:10.1097/ gim.0b013e31818b0d9b

Denisenko, T. V., Pivnyuk, A. D., and Zhivotovsky, B. (2018). p53-AutophagyMetastasis Link. Cancers (Basel) 10. doi:10.3390/cancers10050148

Dittmer, D., Pati, S., Zambetti, G., Chu, S., Teresky, A. K., Moore, M., et al. (1993). Gain of Function Mutations in P53. Nat. Genet. 4, 42-46. doi:10.1038/ ng0593-42

Du, P., Cao, H., Wu, H.-R., Zhu, B.-S., Wang, H.-W., Gu, C.-W., et al. (2013). Blocking Bcl-2 Leads to Autophagy Activation and Cell Death of the HEPG2 Liver Cancer Cell Line. Asian Pac. J. Cancer Prev. 14, 5849-5854. doi:10.7314/ apjcp.2013.14.10.5849

Duffy, A., Le, J., Sausville, E., and Emadi, A. (2015). Autophagy Modulation: a Target for Cancer Treatment Development. Cancer Chemother. Pharmacol. 75, 439-447. doi:10.1007/s00280-014-2637-z

Eby, K. G., Rosenbluth, J. M., Mays, D. J., Marshall, C. B., Barton, C. E., Sinha, S., et al. (2010). ISG20L1 Is a P53 Family Target Gene that Modulates Genotoxic Stress-Induced Autophagy. Mol. Cancer 9, 95. doi:10.1186/ 1476-4598-9-95

Ellert-Miklaszewska, A., Ciechomska, I. A., and Kaminska, B. (2021). Synthetic Cannabinoids Induce Autophagy and Mitochondrial Apoptotic Pathways in Human Glioblastoma Cells Independently of Deficiency in TP53 or PTEN Tumor Suppressors. Cancers (Basel) 13. doi:10.3390/cancers13030419

Eriksson, M., Ambroise, G., Ouchida, A. T., Lima Queiroz, A., Smith, D., GimenezCassina, A., et al. (2017). Effect of Mutant P53 Proteins on Glycolysis and Mitochondrial Metabolism. Mol. Cel Biol 37. doi:10.1128/MCB.00328-17

Falcicchio, M., Ward, J. A., Macip, S., and Doveston, R. G. (2020). Regulation of P53 by the 14-3-3 Protein Interaction Network: New Opportunities for Drug Discovery in Cancer. Cell Death Discov 6, 126. doi:10.1038/s41420-020-00362-3

Fang, R., Wang, X., Xia, Q., Zhao, M., Zhang, H., Wang, X., et al. (2021). Nuclear Translocation of ASPL-TFE3 Fusion Protein Creates Favorable Metabolism by Mediating Autophagy in Translocation Renal Cell Carcinoma. Oncogene 40, 3303-3317. doi:10.1038/s41388-021-01776-8

Feng, Z., Hu, W., de Stanchina, E., Teresky, A. K., Jin, S., Lowe, S., et al. (2007). The Regulation of AMPK $\beta 1$, TSC2, and PTEN Expression by P53: Stress, Cell and Tissue Specificity, and the Role of These Gene Products in Modulating the IGF1-AKT-mTOR Pathways. Cancer Res. 67, 3043-3053. doi:10.1158/00085472.can-06-4149
Gao, L., Ge, C., Wang, S., Xu, X., Feng, Y., Li, X., et al. (2020). The Role of P53Mediated Signaling in the Therapeutic Response of Colorectal Cancer to 9F, a Spermine-Modified Naphthalene Diimide Derivative. Cancers (Basel) 12. doi:10.3390/cancers 12030528

Giaccia, A. J., and Kastan, M. B. (1998). The Complexity of P53 Modulation: Emerging Patterns from Divergent Signals. Genes Dev. 12, 2973-2983. doi:10.1101/gad.12.19.2973

Gottlieb, E., and Vousden, K. H. (2010). p53 Regulation of Metabolic Pathways. Cold Spring Harbor Perspect. Biol. 2, a001040. doi:10.1101/ cshperspect.a001040

Harrison, B., Kraus, M., Burch, L., Stevens, C., Craig, A., Gordon-Weeks, P., et al. (2008). DAPK-1 Binding to a Linear Peptide Motif in MAP1B Stimulates Autophagy and Membrane Blebbing. J. Biol. Chem. 283, 9999-10014. doi:10.1074/jbc.m706040200

He, P., Li, Z., Xu, F., Ru, G., Huang, Y., Lin, E., et al. (2020). AMPK Activity Contributes to G2 Arrest and DNA Damage Decrease via P53/p21 Pathways in Oxidatively Damaged Mouse Zygotes. Front. Cel Dev Biol 8, 539485. doi:10.3389/fcell.2020.539485

Hernández Borrero, L. J., and El-Deiry, W. S. (2021). Tumor Suppressor P53: Biology, Signaling Pathways, and Therapeutic Targeting. Biochim. Biophys. Acta (Bba) - Rev. Cancer 1876, 188556. doi:10.1016/j.bbcan.2021.188556

Hu, L., Wang, Y., Chen, Z., Fu, L., Wang, S., Zhang, X., et al. (2019). Hsp90 Inhibitor SNX-2112 Enhances TRAIL-Induced Apoptosis of Human Cervical Cancer Cells via the ROS-Mediated JNK-P53-Autophagy-DR5 Pathway. Oxid Med. Cel Longev 2019, 9675450. doi:10.1155/2019/9675450

Hurley, J. H., and Young, L. N. (2017). Mechanisms of Autophagy Initiation. Annu. Rev. Biochem. 86, 225-244. doi:10.1146/annurev-biochem-061516-044820

Ingaramo, M. C., Sánchez, J. A., and Dekanty, A. (2018). Regulation and Function of P53: A Perspective from Drosophila Studies. Mech. Development 154, 82-90. doi:10.1016/j.mod.2018.05.007

Jain, A. K., and Barton, M. C. (2018). p53: Emerging Roles in Stem Cells, Development and beyond, Development, 145. doi:10.1242/dev.158360

Jänicke, R. U., Sohn, D., and Schulze-Osthoff, K. (2008). The Dark Side of a Tumor Suppressor: Anti-apoptotic P53. Cel Death Differ 15, 959-976. doi:10.1038/ cdd. 2008.33

Jazvinscak Jembrek, M., Orsolic, N., Mandic, L., Sadzak, A., and Segota, S. (2021). Anti-Oxidative, Anti-inflammatory and Anti-apoptotic Effects of Flavonols: Targeting Nrf2, NF-kappaB and P53 Pathways in Neurodegeneration. Antioxidants (Basel) 10.

Jin, S. (2005). p53, Autophagy and Tumor Suppression. Autophagy 1, 171-173. doi:10.4161/auto.1.3.2051

Jung, S., Jeong, H., and Yu, S.-W. (2020). Autophagy as a Decisive Process for Cell Death. Exp. Mol. Med. 52, 921-930. doi:10.1038/s12276-020-0455-4

Kang, K., Zhu, C., Yong, S., Gao, Q., and Wong, M. (2009). Enhanced Sensitivity of Celecoxib in Human Glioblastoma Cells: Induction of DNA Damage Leading to P53-dependent G1 Cell Cycle Arrest and Autophagy. Mol. Cancer 8, 66. doi:10.1186/1476-4598-8-66

Kardideh, B., Samimi, Z., Norooznezhad, F., Kiani, S., and Mansouri, K. (2019). Autophagy, Cancer and Angiogenesis: where Is the Link? Cell Biosci 9, 65. doi:10.1186/s13578-019-0327-6

Kaushik, S., Massey, A. C., Mizushima, N., and Cuervo, A. M. (2008). Constitutive Activation of Chaperone-Mediated Autophagy in Cells with Impaired Macroautophagy. $M B O C$ 19, 2179-2192. doi:10.1091/mbc.e07-11-1155

Kim, S. M., Ha, S. E., Lee, H. J., Rampogu, S., Vetrivel, P., Kim, H. H., et al. (2020). Sinensetin Induces Autophagic Cell Death through P53-Related AMPK/mTOR Signaling in Hepatocellular Carcinoma HepG2 Cells. Nutrients 12. doi:10.3390/ nu12082462

Kon, N., Ou, Y., Wang, S.-J., Li, H., Rustgi, A. K., and Gu, W. (2021). mTOR Inhibition Acts as an Unexpected Checkpoint in P53-Mediated Tumor Suppression. Genes Dev. 35, 59-64. doi:10.1101/gad.340919.120

Kotani, T., Kirisako, H., Koizumi, M., Ohsumi, Y., and Nakatogawa, H. (2018). The Atg2-Atg18 Complex Tethers Pre-autophagosomal Membranes to the Endoplasmic Reticulum for Autophagosome Formation. Proc. Natl. Acad. Sci. USA 115, 10363-10368. doi:10.1073/pnas.1806727115

Krishnan, S., Shrestha, Y., Jayatunga, D. P. W., Rea, S., Martins, R., and Bharadwaj, P. (2020). Activate or Inhibit? Implications of Autophagy Modulation as a Therapeutic Strategy for Alzheimer's Disease. Int. J. Mol. Sci. 21. doi:10.3390/ ijms 21186739 
Labi, V., Grespi, F., Baumgartner, F., and Villunger, A. (2008). Targeting the Bcl-2Regulated Apoptosis Pathway by BH3 Mimetics: a breAkthrough in Anticancer Therapy? Cel Death Differ 15, 977-987. doi:10.1038/cdd.2008.37

Lacroix, M., Riscal, R., Arena, G., Linares, L. K., and Le Cam, L. (2020). Metabolic Functions of the Tumor Suppressor P53: Implications in normal Physiology, Metabolic Disorders, and Cancer. Mol. Metab. 33, 2-22. doi:10.1016/ j.molmet.2019.10.002

Lee, S. W., Kim, H.-K., Lee, N.-H., Yi, H.-Y., Kim, H.-S., Hong, S. H., et al. (2015). The Synergistic Effect of Combination Temozolomide and Chloroquine Treatment Is Dependent on Autophagy Formation and P53 Status in Glioma Cells. Cancer Lett. 360, 195-204. doi:10.1016/j.canlet.2015.02.012

Lee, Y.-J., and Lee, S.-H. (2017). Pro-oxidant Activity of Sulforaphane and Cisplatin Potentiates Apoptosis and Simultaneously Promotes Autophagy in Malignant Mesothelioma Cells. Mol. Med. Rep. 16, 2133-2141. doi:10.3892/ mmr.2017.6789

Levine, B., and Abrams, J. (2008). p53: The Janus of Autophagy? Nat. Cel Biol 10, 637-639. doi:10.1038/ncb0608-637

Lewinska, A., Adamczyk-Grochala, J., Kwasniewicz, E., Deregowska, A., and Wnuk, M. (2017). Diosmin-induced Senescence, Apoptosis and Autophagy in Breast Cancer Cells of Different P53 Status and ERK Activity. Toxicol. Lett. 265, 117-130. doi:10.1016/j.toxlet.2016.11.018

Li, F., Miao, L., Xue, T., Qin, H., Mondal, S., Thompson, P. R., et al. (2019). Inhibiting PAD2 Enhances the Anti-tumor Effect of Docetaxel in TamoxifenResistant Breast Cancer Cells. J. Exp. Clin. Cancer Res. 38, 414. doi:10.1186/ s13046-019-1404-8

Lin, C.-J., Chen, T.-L., Tseng, Y.-Y., Wu, G.-J., Hsieh, M.-H., Lin, Y.-W., et al. (2016). Honokiol Induces Autophagic Cell Death in Malignant Glioma through Reactive Oxygen Species-Mediated Regulation of the p53/PI3K/Akt/mTOR Signaling Pathway. Toxicol. Appl. Pharmacol. 304, 59-69. doi:10.1016/ j.taap.2016.05.018

Liu, B.-Q., Du, Z.-X., Zong, Z.-H., Li, C., Li, N., Zhang, Q., et al. (2013). BAG3dependent Noncanonical Autophagy Induced by Proteasome Inhibition in HepG2 Cells. Autophagy 9, 905-916. doi:10.4161/auto.24292

Liu, J., Ma, Q., Zhang, M., Wang, X., Zhang, D., Li, W., et al. (2012). Alterations of TP53 Are Associated with a Poor Outcome for Patients with Hepatocellular Carcinoma: Evidence from a Systematic Review and Meta-Analysis. Eur. J. Cancer 48, 2328-2338. doi:10.1016/j.ejca.2012.03.001

Liu, Y., and Gu, W. (2021). The Complexity of P53-Mediated Metabolic Regulation in Tumor Suppression. Semin. Cancer Biol. doi:10.1016/ j.semcancer.2021.03.010

Luo, P., Xu, Z., Li, G., Yan, H., Zhu, Y., Zhu, H., et al. (2018). HMGB1 Represses the Anti-cancer Activity of Sunitinib by Governing TP53 Autophagic Degradation via its Nucleus-To-Cytoplasm Transport. Autophagy 14, 2155-2170. doi:10.1080/15548627.2018.1501134

Maiuri, M. C., Galluzzi, L., Morselli, E., Kepp, O., Malik, S. A., and Kroemer, G. (2010). Autophagy Regulation by P53. Curr. Opin. Cel Biol. 22, 181-185. doi:10.1016/j.ceb.2009.12.001

Maiuri, M. C., Malik, S. A., Morselli, E., Kepp, O., Criollo, A., Mouchel, P.-L., et al. (2009). Stimulation of Autophagy by the P53 Target Gene Sestrin2. Cell Cycle 8, 1571-1576. doi:10.4161/cc.8.10.8498

Mijit, M., Caracciolo, V., Melillo, A., Amicarelli, F., and Giordano, A. (2020). Role of P53 in the Regulation of Cellular Senescence. Biomolecules 10. doi:10.3390/ biom 10030420

Miller, D. R., and Thorburn, A. (2021). Autophagy and Organelle Homeostasis in Cancer. Developmental Cel 56, 906-918. doi:10.1016/ j.devcel.2021.02.010

Moll, U. M., Marchenko, N., and Zhang, X.-k. (2006). p53 and Nur77/TR3 Transcription Factors that Directly Target Mitochondria for Cell Death Induction. Oncogene 25, 4725-4743. doi:10.1038/sj.onc.1209601

Morselli, E., Tasdemir, E., Chiara Maiuri, M., Galluzzi, L., Kepp, O., Criollo, A., et al. (2008). Mutant P53 Protein Localized in the Cytoplasm Inhibits Autophagy. Cell Cycle 7, 3056-3061. doi:10.4161/cc.7.19.6751

Mrakovcic, M., and Fröhlich, L. F. (2018). p53-Mediated Molecular Control of Autophagy in Tumor Cells. Biomolecules 8. doi:10.3390/biom8020014

Mukhopadhyay, S., Mahapatra, K. K., Praharaj, P. P., Patil, S., and Bhutia, S. K. (2021). Recent Progress of Autophagy Signaling in Tumor Microenvironment and its Targeting for Possible Cancer Therapeutics. Semin. Cancer Biol. doi:10.1016/j.semcancer.2021.09.003
Munroe, M., Niero, E. L., Fok, W. C., Vessoni, A. T., Jeong, H. C., Brenner, K. A., et al. (2020). Telomere Dysfunction Activates P53 and Represses HNF4a Expression Leading to Impaired Human Hepatocyte Development and Function. Hepatology 72, 1412-1429. doi:10.1002/hep.31414

Oren, M., and Rotter, V. (2010). Mutant P53 Gain-Of-Function in Cancer. Csh Perspect. Biol. 2. doi:10.1101/cshperspect.a001107

Parrales, A., and Iwakuma, T. (2015). Targeting Oncogenic Mutant P53 for Cancer Therapy. Front. Oncol. 5, 288. doi:10.3389/fonc.2015.00288

Pérez-Hernández, M., Arias, A., Martínez-García, D., Pérez-Tomás, R., Quesada, R., and Soto-Cerrato, V. (2019). Targeting Autophagy for Cancer Treatment and Tumor Chemosensitization. Cancers (Basel) 11. doi:10.3390/ cancers11101599

Pimkina, J., Humbey, O., Zilfou, J. T., Jarnik, M., and Murphy, M. E. (2009). ARF Induces Autophagy by Virtue of Interaction with Bcl-Xl. J. Biol. Chem. 284, 2803-2810. doi:10.1074/jbc.m804705200

Punja, H. K., Nanjappa, D. P., Babu, N., Kalladka, K., Shanti Priya Dias, B., Chakraborty, G., et al. (2021). TP53 Codon 72 Polymorphism and Type 2 Diabetes: a Case-Control Study in South Indian Population. Mol. Biol. Rep. 48, 5093-5097. doi:10.1007/s11033-021-06505-8

Qin, J.-J., Li, X., Hunt, C., Wang, W., Wang, H., and Zhang, R. (2018). Natural Products Targeting the P53-MDM2 Pathway and Mutant P53: Recent Advances and Implications in Cancer Medicine. Genes Dis. 5, 204-219. doi:10.1016/j.gendis.2018.07.002

Rahman, M. A., Cho, Y., Nam, G., and Rhim, H. (2021a). Antioxidant Compound, Oxyresveratrol, Inhibits APP Production through the AMPK/ULK1/mTORMediated Autophagy Pathway in Mouse Cortical Astrocytes. AntioxidantsBasel 10. doi:10.3390/antiox10030408

Rahman, M. A., Hannan, M. A., Dash, R., Rahman, M. H., Islam, R., Uddin, M. J., et al. (2021b). Phytochemicals as a Complement to Cancer Chemotherapy: Pharmacological Modulation of the Autophagy-Apoptosis Pathway. Front. Pharmacol. 12. doi:10.3389/fphar.2021.639628

Rahman, M. A., Rahman, M. D. H., Hossain, M. S., Biswas, P., Islam, R., Uddin, M. J., et al. (2020a). Molecular Insights into the Multifunctional Role of Natural Compounds: Autophagy Modulation and Cancer Prevention. Biomedicines 8. doi:10.3390/biomedicines 8110517

Rahman, M. A., Rahman, M. S., Rahman, M. H., Rasheduzzaman, M., Mamun-OrRashid, A. N. M., Uddin, M. J., et al. (2021c). Modulatory Effects of Autophagy on APP Processing as a Potential Treatment Target for Alzheimer's Disease. Biomedicines 9.

Rahman, M. A., Saha, S. K., Rahman, M. S., Uddin, M. J., Uddin, M. S., Pang, M. G., et al. (2020b). Molecular Insights into Therapeutic Potential of Autophagy Modulation by Natural Products for Cancer Stem Cells. Front. Cel Dev Biol 8, 283. doi:10.3389/fcell.2020.00283

Rahman, M. A., and Rhim, H. (2017). Therapeutic Implication of Autophagy in Neurodegenerative Diseases. BMB Rep. 50, 345-354. doi:10.5483/ bmbrep.2017.50.7.069

Rahman, M. A., Uddin, M. J., Mamun-Or-Rashid, A. N. M., Pang, M. R. M.-G., and Rhim, H.ANM Mamun-Or-Rashid (2020). Proteostasis and Neurodegeneration. Qual. Control. Cell Protein Neurodegenerative Disord. IGI Glob., 154-178. doi:10.4018/978-1-7998-1317-0.ch006

Rangel, M., Kong, J., Bhatt, V., Khayati, K., and Guo, J. Y. (2021). Autophagy and Tumorigenesis. FEBS J. doi:10.1111/febs.16125

Rubinsztein, D. C., Shpilka, T., and Elazar, Z. (2012). Mechanisms of Autophagosome Biogenesis. Curr. Biol. 22, R29-R34. doi:10.1016/ j.cub.2011.11.034

Saini, H., Sharma, H., Mukherjee, S., Chowdhury, S., and Chowdhury, R. (2021). Verteporfin Disrupts Multiple Steps of Autophagy and Regulates P53 to Sensitize Osteosarcoma Cells. Cancer Cel Int 21, 52. doi:10.1186/s12935020-01720-y

Shi, K., An, J., Qian, K., Zhao, X., Li, F., Ma, X., et al. (2020a). p53 Controls the Switch between Autophagy and Apoptosis through Regulation of PLSCR1 in Sodium Selenite-Treated Leukemia Cells. Exp. Cel Res. 389, 111879. doi:10.1016/j.yexcr.2020.111879

Shi, Y., Norberg, E., and Vakifahmetoglu-Norberg, H. (2020b). Mutant P53 as a Regulator and Target of Autophagy. Front. Oncol. 10, 607149.

Shim, D., Duan, L., and Maki, C. G. (2021). P53-regulated Autophagy and its Impact on Drug Resistance and Cell Fate. Cdr 4, 85-95. doi:10.20517/ cdr.2020.85 
Soussi, T. (2000). The P53 Tumor Suppressor Gene: From Molecular Biology to Clinical Investigation. Ann. N. Y Acad. Sci. 910, 121-129. doi:10.1111/j.17496632.2000.tb06705.x

Soussi, T., and Wiman, K. G. (2007). Shaping Genetic Alterations in Human Cancer: the P53 Mutation Paradigm. Cancer Cell 12, 303-312. doi:10.1016/ j.ccr.2007.10.001

Subburayan, K., Thayyullathil, F., Pallichankandy, S., Rahman, A., and Galadari, S. (2018). Par-4-dependent P53 Up-Regulation Plays a Critical Role in Thymoquinone-Induced Cellular Senescence in Human Malignant Glioma Cells. Cancer Lett. 426, 80-97. doi:10.1016/j.canlet.2018.04.009

Sui, X., Jin, L., Huang, X., Geng, S., He, C., and Hu, X. (2011). p53 Signaling and Autophagy in Cancer: a Revolutionary Strategy Could Be Developed for Cancer Treatment. Autophagy 7, 565-571. doi:10.4161/auto.7.6.14073

Tang, J., Peng, W. Y., Feng, Y. X., Le, X., Wang, K., Xiang, Q., et al. (2021b). Cancer Cells Escape P53's Tumor Suppression through Ablation of ZDHHC1Mediated P53 Palmitoylation. Oncogene. doi:10.1038/s41388-021-01949-5

Tang, J., Chen, L., Qin, Z.-h., and Sheng, R. (2021a). Structure, Regulation, and Biological Functions of TIGAR and its Role in Diseases. Acta Pharmacol. Sin 42, 1547-1555. doi:10.1038/s41401-020-00588-y

Tasdemir, E., Maiuri, M. C., Galluzzi, L., Vitale, I., Djavaheri-Mergny, M., D'Amelio, M., et al. (2008a). Regulation of Autophagy by Cytoplasmic P53. Nat. Cel Biol 10, 676-687. doi:10.1038/ncb1730

Tasdemir, E., Maiuri, M. C., Orhon, I., Kepp, O., Morselli, E., Criollo, A., et al. (2008b). p53 Represses Autophagy in a Cell Cycle-dependent Fashion. Cell Cycle 7, 3006-3011. doi:10.4161/cc.7.19.6702

Thorburn, A. (2014). Autophagy and its Effects: Making Sense of Double-Edged Swords. Plos Biol. 12. doi:10.1371/journal.pbio.1001967

Tripathi, R., Ash, D., and Shaha, C. (2014). Beclin-1-p53 Interaction Is Crucial for Cell Fate Determination in Embryonal Carcinoma Cells. J. Cel. Mol. Med. 18, 2275-2286. doi:10.1111/jcmm.12386

Uddin, M. S., Mamun, A. A., Jakaria, M., Thangapandiyan, S., Ahmad, J., Rahman, M. A., et al. (2020a). Emerging Promise of Sulforaphane-Mediated Nrf2 Signaling cascade against Neurological Disorders. Sci. Total Environ. 707, 135624. doi:10.1016/j.scitotenv.2019.135624

Uddin, M. S., Rahman, M. A., Kabir, M. T., Behl, T., Mathew, B., Perveen, A., et al. (2020b). Multifarious Roles ofmTORsignaling in Cognitive Aging and Cerebrovascular Dysfunction of Alzheimer's Disease. Iubmb Life 72, 1843-1855. doi:10.1002/iub.2324

Ueda, Y., Koya, T., Yoneda-Kato, N., and Kato, J.-y. (2008). Small Mitochondrial ARF (smARF) Is Located in Both the Nucleus and Cytoplasm, Induces Cell Death, and Activates P53 in Mouse Fibroblasts. FEBS Lett. 582, 1459-1464. doi:10.1016/j.febslet.2008.03.032

Ulbricht, A., Eppler, F. J., Tapia, V. E., van der Ven, P. F. M., Hampe, N., Hersch, N., et al. (2013). Cellular Mechanotransduction Relies on Tension-Induced and Chaperone-Assisted Autophagy. Curr. Biol. 23, 430-435. doi:10.1016/ j.cub.2013.01.064

Vakifahmetoglu-Norberg, H., Kim, M., Xia, H.-g., Iwanicki, M. P., Ofengeim, D., Coloff, J. L., et al. (2016). Corrigendum: Chaperone-Mediated Autophagy Degrades Mutant P53. Genes Dev. 30, 870. doi:10.1101/gad.280453.116

Verma, A. K., Bharti, P. S., Rafat, S., Bhatt, D., Goyal, Y., Pandey, K. K., et al. (2021). Autophagy Paradox of Cancer: Role, Regulation, and Duality. Oxid Med. Cel Longev 2021, 8832541. doi:10.1155/2021/8832541

Wang, J., Liu, D., Sun, Z., Ye, T., Li, J., Zeng, B., et al. (2021a). Autophagy Augments the Self-Renewal of Lung Cancer Stem Cells by the Degradation of Ubiquitinated P53. Cell Death Dis 12, 98. doi:10.1038/s41419-02103392-6

Wang, Z. X., Ma, J., Li, X. Y., Wu, Y., Shi, H., Chen, Y., et al. (2021b). Quercetin Induces P53-independent Cancer Cell Death through Lysosome Activation by the Transcription Factor EB and Reactive Oxygen Species-dependent Ferroptosis. Br. J. Pharmacol. 178, 1133-1148. doi:10.1111/bph.15350

Wei, Y., and Huang, J. (2019). Role of Estrogen and its Receptors MediatedAutophagy in Cell Fate and Human Diseases. J. Steroid Biochem. Mol. Biol. 191, 105380. doi:10.1016/j.jsbmb.2019.105380
Wen, J., and Wang, D. (2021). Deciphering the PTM Codes of the Tumor Suppressor P53. J. Mol. Cel Biol. doi:10.1093/jmcb/mjab047

White, E. (2015). The Role for Autophagy in Cancer. J. Clin. Invest. 125, 42-46. doi:10.1172/jci73941

Williams, A. B., and Schumacher, B. (2016). p53 in the DNA-Damage-Repair Process. Cold Spring Harb Perspect. Med. 6. doi:10.1101/ cshperspect.a026070

Xu, J., Wang, Y., Wang, Y., Wang, Z., and He, X. (2021). A-24, a Steroidal Saponin from Allium Chinense, Induced Apoptosis, Autophagy and Migration Inhibition in P53 Wild-type and P53-Deficient Gastric Cancer Cells. Chemico-Biological Interactions 348, 109648. doi:10.1016/j.cbi.2021.109648

Xu, J., Wu, Y., Lu, G., Xie, S., Ma, Z., Chen, Z., et al. (2017). Importance of ROS-Mediated Autophagy in Determining Apoptotic Cell Death Induced by Physapubescin B. Redox Biol. 12, 198-207. doi:10.1016/ j.redox.2017.02.017

Yan, R. L., and Chen, R. H. (2021). Autophagy and Cancer Metabolism-The TwoWay Interplay. Iubmb Life. 15. doi:10.1002/iub.2569

Yao, Z., Xie, F., Li, M., Liang, Z., Xu, W., Yang, J., et al. (2017). Oridonin Induces Autophagy via Inhibition of Glucose Metabolism in P53-Mutated Colorectal Cancer Cells. Cel Death Dis 8, e2633. doi:10.1038/cddis.2017.35

Yee, K. S., Wilkinson, S., James, J., Ryan, K. M., and Vousden, K. H. (2009). PUMAand Bax-Induced Autophagy Contributes to Apoptosis. Cel Death Differ 16, 1135-1145. doi:10.1038/cdd.2009.28

Yoo, H. S., Won, S. B., and Kwon, Y. H. (2021). Luteolin Induces Apoptosis and Autophagy in HCT116 Colon Cancer Cells via P53-dependent Pathway. Nutr. Cancer, 1-10. doi:10.1080/01635581.2021.1903947

Zalckvar, E., Berissi, H., Eisenstein, M., and Kimchi, A. (2009a). Phosphorylation of Beclin 1 by DAP-Kinase Promotes Autophagy by Weakening its Interactions with Bcl-2 and Bcl-XL. Autophagy 5, 720-722. doi:10.4161/ auto.5.5.8625

Zalckvar, E., Berissi, H., Mizrachy, L., Idelchuk, Y., Koren, I., Eisenstein, M., et al. (2009b). DAP-kinase-mediated Phosphorylation on the BH3 Domain of Beclin 1 Promotes Dissociation of Beclin 1 from Bcl-XL and Induction of Autophagy. EMBO Rep. 10, 285-292. doi:10.1038/embor.2008.246

Zawacka-Pankau, J., and Selivanova, G. (2015). Pharmacological Reactivation of P53 as a Strategy to Treat Cancer. J. Intern. Med. 277, 248-259. doi:10.1111/ joim. 12336

Zhang, B., Yin, X., and Sui, S. (2018). Resveratrol Inhibited the Progression of Human Hepatocellular Carcinoma by Inducing Autophagy via Regulating P53 and the Phosphoinositide 3-kinase/protein kinase B P-athway. Oncol. Rep. 40, 2758-2765. doi:10.3892/or.2018.6648

Zhu, Y., He, W., Gao, X., Li, B., Mei, C., Xu, R., et al. (2015). Resveratrol Overcomes Gefitinib Resistance by Increasing the Intracellular Gefitinib Concentration and Triggering Apoptosis, Autophagy and Senescence in PC9/G NSCLC Cells. Sci. Rep. 5, 17730. doi:10.1038/srep17730

Conflict of Interest: The authors declare that the research was conducted in the absence of any commercial or financial relationships that could be construed as a potential conflict of interest.

Publisher's Note: All claims expressed in this article are solely those of the authors and do not necessarily represent those of their affiliated organizations, or those of the publisher, the editors and the reviewers. Any product that may be evaluated in this article, or claim that may be made by its manufacturer, is not guaranteed or endorsed by the publisher.

Copyright () 2022 Rahman, Park, Rahman, Rashid, Islam, Uddin, Hannan and Kim. This is an open-access article distributed under the terms of the Creative Commons Attribution License (CC BY). The use, distribution or reproduction in other forums is permitted, provided the original author(s) and the copyright owner(s) are credited and that the original publication in this journal is cited, in accordance with accepted academic practice. No use, distribution or reproduction is permitted which does not comply with these terms. 